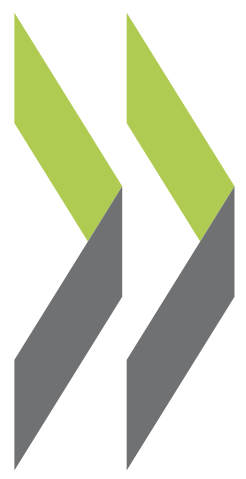

SIGMA Papers No. 51

Policy Making Review

Montenegro

\title{
Klas Klaas
}

https://dx.doi.org/10.1787/5jz15qwrt2vb-en 


\title{
SIGMA
}

\section{Policy Making Review \\ Montenegro}

\author{
SIGMA PAPER No. 51
}

Authorised for publication by Karen Hill, Head of the SIGMA Programme 


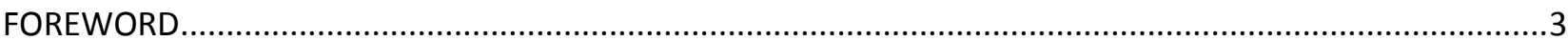

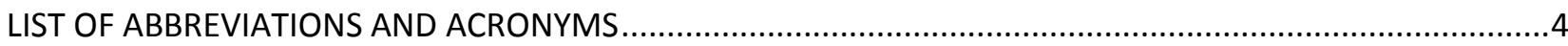

EXECUTIVE SUMMARY AND KEY RECOMMENDATIONS ...................................................................

1 POLICY PLANNING AND CO-ORDINATION IN THE GOVERNMENT ..............................................

1.1 Overall legal framework for policy co-ordination within the Government .................................9

1.2 Policy co-ordination and planning arrangements at the centre of government .........................10

1.2.1 Coherence of the centre of government.......................................................................11

1.2.2 General Secretariat of the Government....................................................................14

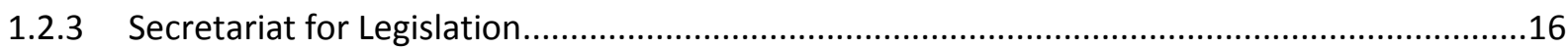

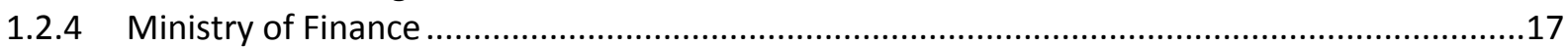

1.2.5 Ministry of Foreign Affairs and European Integration ......................................................18

1.3 Main horizontal policy making processes ...........................................................................20

1.3.1 Co-ordination of the Government's strategic priorities, annual Government Work Programme

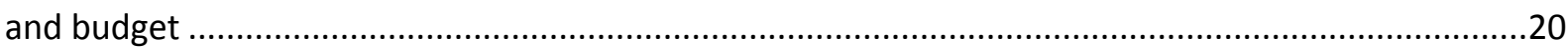

1.3.2 Co-ordination of European integration plans and strategies.............................................22

1.3.3 Co-ordination, preparation and communication of government sessions .............................25

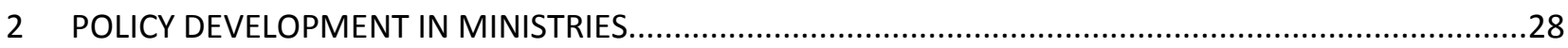

2.1 Legislative framework for policy development and interministerial co-operation .......................28

2.2 Policy development arrangements and capacity in the ministries...........................................29

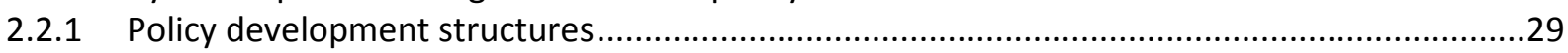

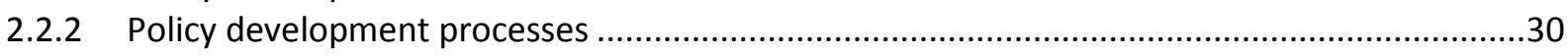

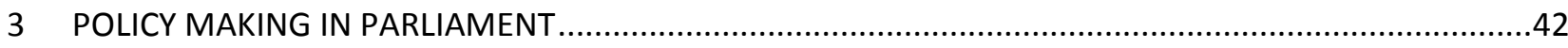

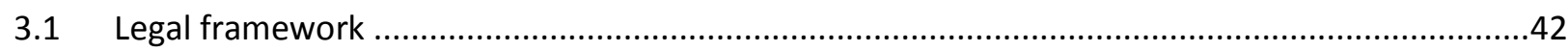

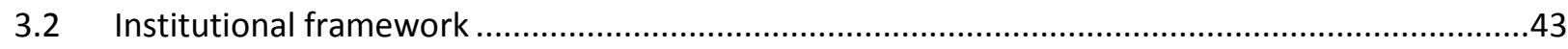

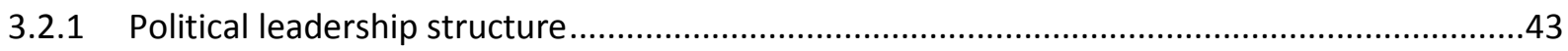

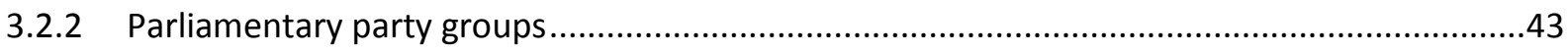

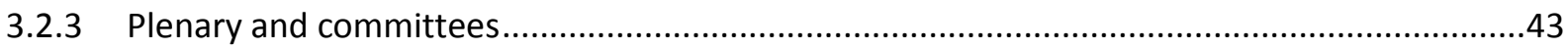

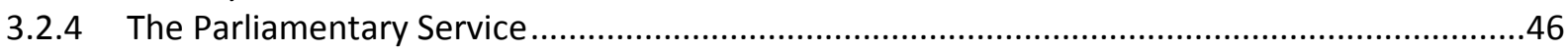

3.3 Key policy processes and instruments ..........................................................................47

3.3.1 Managing parliamentary business and inter-institutional relationships .............................47

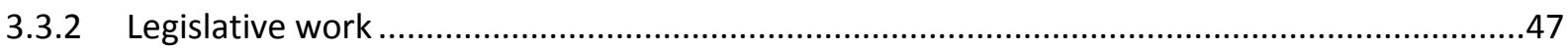

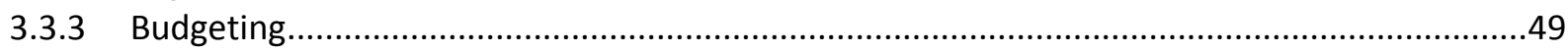

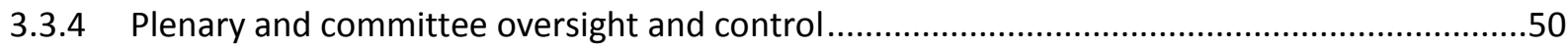

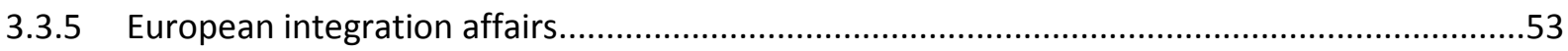

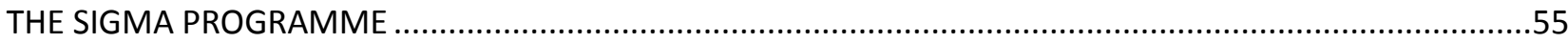




\section{FOREWORD}

A fully functioning national public administration is a prerequisite for a transparent and effective democratic system. Although there is no formal acquis in this area, the EU enlargement criteria recognise and emphasise the need for a country to build an effective public administration. As Montenegro prepares itself for EU membership, the connection between an effective public administration and European integration becomes more evident.

The preparations for the EU accession and membership need to be underpinned by policy planning, development, co-ordination and implementation arrangements that:

- $\quad$ enable consistent policy planning and co-ordination of government activities, including priority setting;

- create policies that are not deficient in substance, are consistent with one another, and are economically efficient and financially sustainable;

- $\quad$ ensure that policies are properly implemented and monitored;

- $\quad$ support transposition and implementation of the acquis in all sectors;

- $\quad$ ensure that foreign assistance supports implementation of government priorities and has a clear added value to national funds;

- $\quad$ lay the foundations for operating effectively as an EU Member State.

The requirements for policy planning, development, co-ordination and implementation arrangements and capacities need to be enhanced as a country moves along the El path. Montenegro is at a crucial stage of the EU accession process, with negotiations moving to a phase where national co-ordination and policy capacities need to by systematic, thorough and agile at the same time.

This review builds on the experience of SIGMA working with Montenegro in a number of areas of public governance. It contains some descriptive material, but the emphasis is on highlighting potential bottlenecks in the policy making processes of the executive and legislative branches.

This review draws on a range of materials, including national legislation in Montenegro, information collected by a NGO Institut Alternativa on behalf of SIGMA, the European Commission's regular Progress Reports, sample Regulatory Impact Assessments prepared by the ministries, publicly available strategies, the annual Government Work Programmes, the Action Plan for Strengthening of the Legislative and Oversight Role of the Parliament of Montenegro in 2013, as well as numerous interviews with practitioners in the Montenegrin administration.

The review was led by Klas Klaas of the OECD SIGMA programme, with substantial expert contributions from Juhan Lepassaar from the Estonian Government Office, Klaus Goetz from the University of Munich and Rachel Holloway from the OECD SIGMA programme. Keit Kasemets and other SIGMA colleagues have provided valuable feedback and support in preparing and finalising the review. 
CoG centre of government

DGEA Directorate General for European Affairs

EI European integration

GO Government Office

GSG General Secretariat of the Government

IPA Instrument for Pre-Accession Assistance

MFAEI Ministry of Foreign Affairs and European Integration

MoF Ministry of Finance

MP Member of Parliament

NGO non-governmental organisation

NIPAC National Instrument for Pre-Accession Assistance (IPA) Co-ordinator

NPA National Programme of Accession

OECD Organisation for Economic Co-operation and Development

PMO Prime Minister's Office

PR public relations

RIA Regulatory Impact Assessment

RoP Rules of Procedure of the Government

SAA Stabilisation and Association Agreement

SIGMA Support for Improvement in Governance and Management

SME small and medium-sized enterprises 


\section{EXECUTIVE SUMMARY AND KEY RECOMMENDATIONS}

\section{Policy planning and co-ordination in the Government}

The first part of this review analyses the functioning of the centre of government (CoG) in Montenegro. The institutions fulfilling the functions of the CoG in Montenegro are the General Secretariat of the Government (GSG), the Secretariat for Legislation, the Ministry of Foreign Affairs and European Integration (MFAEI) and the Ministry of Finance (MoF). Overall, the roles of these four key organisations are well established and there is sufficient clarity in responsibilities. Co-ordination among them often happens on the basis of need to interact to fulfil common tasks. On a more permanent basis, each of the central bodies co-ordinates and interacts primarily with the line ministries.

Montenegro has allocated most of the key functions of the CoG, with some limitations in three out of the nine functions defined by SIGMA:

- There is no clear centre for co-ordinating strategic priorities at the administrative level, although, in practice, government strategic documents are broadly consistent.

- $\quad$ For co-ordinating the policy content of proposals for government decision, the GSG does not have the resources for substantial work, except by the advisory staff of the Prime Minister and the Deputy Prime Ministers.

- Monitoring the progress of government work is focussed on the fulfilment of activities under the annual Government Work Programme. Wider analysis of government work performance is not done centrally, although reports on the implementation of government conclusions and reports on the work of ministries are prepared.

Existing regulation for regular government decision making and annual work planning is clear and largely implemented in practice. There is a good system in place for preparing the annual Government Work Programme.

The main weaknesses are related to the lack of formal requirements for medium-term policy resource planning. There are no particular requirements for sector strategies and the medium-term budgetary framework is not developed to capture sector policies or their resource needs. The majority of sector strategies either do not have any information on estimated financing needs or sources of funding or, where financing needs are presented, they are not in line with the actual resource plans of the country (e.g. the annual budget or the Instrument for Pre-Accession Assistance [IPA] programmes).

While the existing rules set the procedural framework and the main requirements for new policy proposals, they do not include specific follow-up obligations for ministries to analyse the implementation of policies.

Regarding overall European integration (EI) co-ordination, Montenegro has developed a dynamic and fairly decentralised framework whereby the MFAEI provides political and administrative leadership on all El-related processes, and the line ministries are responsible for analytical and preparatory tasks related to their specific policy areas.

Although there is a comprehensive medium-term framework strategy for EU accession (the Programme of Accession of Montenegro), there is a consistent problem prioritising allocation of resources. With the current planning framework, accession-related tasks are split between negotiation chapters, making prioritisation difficult at the government level. Also within the negotiation chapters prioritisation of work is not in many cases apparent. The Programme of Accession of Montenegro 20142018 is nevertheless a useful document to capture the different commitments, and the MFAEI can use it to monitor ministry work in sufficient detail. 


\section{Key recommendations}

- Define the purpose of, and establish minimum requirements for, all medium-term government planning documents to ensure systematic policy inputs to IPA planning and medium-term budget planning.

- For greater transparency, consolidate all medium-term and annual government planning documents (both horizontal and sectoral), and systematically publish them on the Government website.

- Following adoption of the Law on Budget and Fiscal Responsibility, develop a coherent medium-term budgetary framework with clear links between government policy and resources.

- Define and establish rules requiring more specific analysis and reporting of the level of, and problems with, the implementation of key laws in Montenegro. To make the task feasible, the focus should be only on key legislation.

- $\quad$ Over time, strengthen the internal capacities of the GSG to review the content of draft government policies for coherence with previous commitments and priorities.

- Organise existing MoF resources to better monitor sector policies and scrutinise fiscal impact estimations of new policy proposals: share joint resources between the Sector for Budget and the Sector for Economic Policy and Development.

- $\quad$ Further develop the Programme of Accession of Montenegro to include more specific prioritisation of actions at the level of the Government and within each negotiation chapter, and to include information on fiscal impact estimations for the negotiation chapters.

\section{Policy development in the ministries}

The ministries in Montenegro are small compared to their functions. Most ministries lack analytical staff, and thorough knowledge of policies is held by a small number of experts (often the general directors). These constraints are often resolved by external consultants engaged for policy analyses and preparation, a practice that undermines capacity building within ministries. The Government risks losing the opportunity to acquire skills of benefit after accession and, more immediately, needed to analyse the implementation of these policies.

Ministries do not have dedicated legal departments and there is a lack of staff with professional skills in law drafting. Similarly, there is a lack of staff able to support economic analyses and fiscal impact estimations.

A number of ministries have or plan to establish El co-ordination units. In a few cases, existing units are tasked with this function or a contact point of EU accession co-ordination is appointed. All of these models are fine, as the volume of El-related obligations varies among ministries.

Most officials fulfil accession-related functions in addition to other duties, which is not a shortcoming; increasingly, integration will require all 'domestic' policy making be achieved through the lens of EU accession goals, avoiding the artificial separation of accession-related tasks from 'normal' tasks that still employ separate staff to perform them.

Planning of EU accession-related activities in the ministries has so far also been ad hoc and plans have not included the budgetary costs of commitments made. This should change with the new updates to the Programme of Accession. The adoption of negotiation positions and commitments in general in the Government must be conducted and channelled through the normal consultative mechanisms.

Regulations, such as the Rules of Procedure of the Government, clearly prescribe what issues must be covered in the paperwork submitted to government sessions to justify a policy proposal-including minimum information on public consultation and opinions of the key ministries - and the regulation is implemented routinely. The Regulatory Impact Assessment (RIA) requirement was established in early 2012 and RIA documents are routinely prepared. Yet, the quality of RIA analysis still varies and RIA documents are too often prepared just before submitting material to the Government. 


\section{Key recommendations}

- As part of implementing the Plan for Internal Restructuring of Public Sector, encourage ministries to shift staffing capacities within their sectors from lower priority and unreformed functions towards core policy staff covering both national and EU policy affairs.

- $\quad$ Establish procedures for ministries to plan their finances and human resources for at least a three year period within their overall sector policy plans.

- Change the existing rules regarding RIA preparation to ensure that i) first RIA documents are prepared before public consultation, ii) updated versions are prepared before government decision, and iii) draft laws to be presented to Parliament are accompanied by the RIA documents.

- Strengthen monitoring of the implementation of the Legal and Technical Rules for drafting legislation, including the provision requiring draft secondary legislation be prepared by the time primary legislation is presented to the Government.

- Develop and implement dedicated training and capacity building programmes for key ministry staff to professionalise policy analysis and legislative drafting work.

- Ensure adoption of negotiation positions and El-related commitments are conducted and channelled through the normal consultative mechanisms. Make each draft negotiation position and other commitments available for scrutiny by the MoF before decisions are made by the Government.

\section{Policy making in the Parliament of Montenegro}

The framework regulating the policy-related powers of the Montenegrin Parliament, including the Rules of Procedure of the Parliament, is comprehensive. However, there is no specific legal framework regulating co-operation between the Government and Parliament concerning El policy.

Although the political leadership structure of Parliament is generally co-operative and advance timetabling works well under normal circumstances, no representative of the Government takes part in the meetings of the Collegium of the Parliament.

The main political working bodies in Parliament are the plenary and the 14 standing committees. Committee membership varies between 11 and 13 deputies, and committees are served by two to seven staff of the Parliamentary Service. The significant variance in the workload among committees is broadly reflected by staffing levels. The Legislative Committee and the Economy, Finance and Budget Committee stand out as having particularly high workloads.

Parliamentary committees account for a high number of proposed amendments to draft laws: over half. The Legislative Committee accounts for most of those adopted. These figures suggest that parliamentary scrutiny is more focussed on legal issues or that it is more effective when focussed on legal issues.

The Committee for European Integration is responsible for overseeing accession negotiations, issuing relevant opinions and guidelines, and assessing the "performance of the negotiating team of the Government". The task of ensuring legal harmonisation has been decentralised to the sectoral committees. The decision to separate the oversight of negotiation (done in the Committee for European Integration) from the oversight of monitoring the approximation of legislation with EU law and the implementation of the National Programme of Accession (done by the line committees) requires well co-ordinated processes and sharing of expertise within Parliament. Deciding negotiation positions is essentially about deciding what kind of commitments and in which time-frame a country should take.

Parliament exercises control hearings and parliamentary enquiries - "fire alarm" instruments of oversight and control. By contrast, "police patrols" (i.e. those allowing Parliament to carry out systematic assessments of executive action, notably the implementation of major laws and policies) do not yet exist.

The Parliamentary Service employs some 147 staff, including trainees. The organisational development of the Parliamentary Service has been significant and positive for a number of years. The organisational 
structure has been modified, e.g. by strengthening the sector supporting the legislative and oversight functions of Parliament and creating a Research and Analysis Unit.

\section{Key recommendations}

- Regulate executive-legislative relations in El affairs at the level of a law and in the binding agreements between the Government and Parliament. The more integration advances, the more EU affairs pervade all aspects of parliamentary activity.

- Open Collegium consultation to a representative of the Government to act as a source of information and to facilitate consultation regarding the number of bills before Parliament and the timing of submission of legislation by the Government.

- $\quad$ Add oversight instruments geared toward enhancing institutional and policy performance through systematic, cross-partisan assessments of the implementation of major laws and policies.

- Split the remit of the Economy, Finance and Budget Committee, potentially by creating two committees: one concentrating on economy and finance, the other on budget and final accounts. Sub-committees could also be considered.

- Analyse options for more flexibility in re-allocation of committee support staff to balance cross-cutting tasks (e.g. checking compliance of bills with EU law or organising consultative and control hearings) with advantageous staff specialisation and close working relations between administrative staff and deputies.

- Institutionalise the emerging practice whereby chairs (or vice-chairs) of line committees and political groups are also members of the Committee for European Integration, ensuring a productive link between discussions held in each arena. 
The first part reviews the regulatory framework of the executive in policy making and co-ordination, the main institutions co-ordinating government policy processes and their ability to work together. Three horizontal policy processes are then analysed in greater detail, focussing on government work planning, EU accession co-ordination and the decision making procedures of the Government.

\subsection{Overall legal framework for policy co-ordination within the Government}

Legal requirements for planning and co-ordinating the work of the Government are in place. The key legal grounds for the work of the ministries for policy planning and co-ordination are: i) the Rules of Procedure of the Government ${ }^{1}$ RoP); ii) the Decree on Government ${ }^{2}$; iii) the Law on State Administration; and iv) the Law on Budget and Fiscal Responsibility. The legal framework specifies the mandate of the Government, its decision making authority, its relations with Parliament and the overall system of government working bodies. The regulations also specify the responsibilities of the General Secretariat of the Government (GSG), provide authority to assume these responsibilities, and create a framework for co-ordinating activities among key institutions at the centre of government ${ }^{3}$ (COG), namely the GSG, the Ministry of Foreign Affairs and European Integration (MFAEI), the Ministry of Finance (MoF) and the Secretariat for Legislation.

Division of responsibilities among line ministries is spelled out in the Government Decree on Organisation and Manner of Operation of the State Administration ${ }^{4}$. The GSG also has some informal authority to resolve conflict of competencies when responsibility is not clear, although formal responsibility is with the Government.

The legislative framework stipulates two central planning documents: the annual Government Work Programme and the annual budget. Both have an annual dimension with some multi-annual character in the supporting documents within the budget process.

The Government's decision making procedures are mainly defined in the RoP. The RoP regulates in detail the process of preparing meetings of the Government, as well as the organisational and procedural aspects of the meetings. The RoP also regulates the decision making procedures of the Government, including the role of four government commissions, which are permanent working bodies of the Government.

Rules defining public consultation and inclusion of non-governmental stakeholders into the work of the ministries are regulated by the two decrees: the Decree on the Procedure and Manner of Public Debate in Preparation of Laws, and the Decree on the Manner and Procedure of Co-operation Between State Administration Authorities and Non-Governmental Organisations (NGO).

The current legislative and regulative framework in force for governing El processes has been mainly established by the Government decisions and decrees promulgated in 2012. In February 2012, the Government adopted a decision establishing a structure for preparing and conducting the EU accession negotiations of Montenegro into the European Union ${ }^{5}$. This decision laid down structures separate from the co-ordination mechanisms related to the Stabilisation and Association Agreement (SAA).

\footnotetext{
1 Official Gazette of Montenegro, 03/12.

2 Official Gazette of Montenegro, 80/08.

3 The notion of the centre of government includes a number of horizontal policy co-ordination functions, which, in Montenegro, are largely fulfilled by the General Secretariat of the Government (GSG), the Ministry of Finance (MoF), the Ministry of Foreign Affairs and European Integration (MFAEI) and the Secretariat for Legislation.

4 Official Gazette of Montenegro, 5/12 as of 23 January 2012, and 25/12 as of 11 May 2012.

5 Official Gazette of Montenegro, 9/12.
} 


\section{Assessment}

The existing regulation is clear and precise for regular government decision making and for annual work planning, and is largely implemented in practice. The RoP clearly specifies the documents that must be presented to support items on which the Government must make a decision at its sessions. It is also precise about the different working bodies of the Government and provides a reasonable mandate for the GSG to support government decision making. The Government's role in the work of Parliament is also regulated and enables the Government to give its expert opinion on the changes and new proposals initiated by Members of Parliament (MP).

The main weaknesses are related to the lack of formal requirements for medium-term policy planning and resource planning. The Law on Budget and Fiscal Responsibility does not foresee consideration of the existing strategic planning framework during the formulation and drafting of the annual budget proposal except in a very abstract way, by stating that budget planning is based on considering, among other things, adopted laws and other regulations ${ }^{6}$. The Law on Budget and Fiscal Responsibility, which has replaced the previous Law on Budget, introduces new elements for fiscal rules and carefully foresees elements for medium-term budget planning. For the time being, the new Law on Budget and Fiscal Responsibility has not been implemented and it provides only a general mandate for the Government to put more effort into medium-term resource planning. Without precise guidelines and requirements by the MoF, these provisions will not bring about decisive changes in the development of a medium-term budgetary framework, as defined by the $\mathrm{EU}^{7}$.

While the RoP set the procedural framework and the main requirements for new policy proposals, including detailed requirements for policy preparation, they lack the specific follow-up obligations needed for the ministries to analyse the implementation of policies. The Law on State Administration places the responsibility for monitoring the implementation of laws and other regulations with the ministries, but is not specific enough to trigger systematic attention to policy implementation. This shortcoming is common to many countries also in the EU, but since the EU accession negotiations are increasingly focussing on implementation, some systematic attention to the analysis of implementation of key regulation related with the acquis is necessary. The Law on State Administration includes obligations for reporting and these reports include some information on the implementation of policies, but since there are no detailed guidelines for the preparation of these reports, ministries have a flexible approach in implementing this obligation.

The El related roles of the MFAEI and other actors are well defined and detailed in the regulatory framework. Interministerial horizontal bodies and procedures that ensure proper consultations within the different government stakeholders (as well as with outside interest groups) have been established. Although there is no direct contradiction of tasks, there are indications of direct overlap in some roles and indirect overlap in the fulfilment of some functions. Direct overlap is notable in the tasks given to different actors by the Government's decisions from February through May 2012, especially as regards the functions of the two sets of working groups (one for negotiations, the other for the SAA process). In reality, those two processes deal with the same content: drafting negotiation positions in the association and accession process, which depends on the ability to make and implement commitments that, to a large extent, would be essentially identical.

\subsection{Policy co-ordination and planning arrangements at the centre of government}

The Government is composed of 19 members: the Prime Minister, four Deputy Prime Ministers (three of whom are also ministers leading individual ministries), 13 ministers and one minister without portfolio. Most of the actual decision making in Montenegro is placed among the political leaders: the ministers. Nevertheless, the analytical and administrative work at the CoG is divided among four key institutions: the GSG, the MFAEI, the MoF and the Secretariat for Legislation.

7 Council Directive 2011/85/EU on Requirements for Budgetary Frameworks of the Member States. 


\subsubsection{Coherence of the centre of government}

The main body responsible for supporting and managing the decision making system is the GSG. Since independence in 2006, the GSG has taken a conscious, step-by-step approach to reforming itself and the policy management system, and to bringing them into closer conformity with European practices. It supports the weekly government sessions and co-ordinates the annual Government Work Programme. The Cabinet of the Prime Minister and the respective cabinets of the Deputy Prime Ministers - part of the GSG - also play a role in policy making.

The Secretariat for Legislation plays a co-ordinating role within the policy system by performing a legal oversight role, which includes ensuring conformity with the Constitution and other legal acts, as well as legal linguistic coherence.

The MoF is involved in policy co-ordination primarily through four mutually supporting roles: i) preparing macroeconomic and fiscal policy estimates; ii) co-ordinating structural reforms and some key economic policy plans, such as the Development Directions of Montenegro; iii) quality control over Regulatory Impact Assessment (RIA) documents, including fiscal impacts; and iv) budget preparation.

The MFAEI co-ordinates planning of Instrument for Pre-Accession Assistance (IPA) programmes and the work of the Government for all El affairs, including transposition of the acquis and managing the EU accession negotiations.

At the political level, the nucleus of co-ordination and government decision making is the inner Cabinet ${ }^{8}$, which meets, as a rule, once a week. It is comprised of the Prime Minister, Deputy Prime Ministers and Secretary General. Among other things, its task is to co-ordinate and consider key issues on the agenda of the Government. Other ministers are invited to take part in the work of the inner Cabinet as needed. Informal meetings of the representatives of the key government bodies take place almost on a daily basis.

European integration (EI) affairs are led by the Deputy Prime Minister and Minister for Foreign Affairs and European Integration, with close support from the State Secretary for European Integration, who is seen as the centre of gravity for the EU accession process. As well as being the State Secretary for El in the ministry, he is also the Chief Negotiator and the National IPA Co-ordinator (NIPAC). He regularly participates in government sessions. All matters relating to the negotiations should, in principle, be discussed in the Collegium ${ }^{9}$, as the primary working body of the Government for El affairs. This body considers the proposed negotiating positions during the stage that follows the working groups' preparation of the drafts and before adoption by the Government.

In recent years, the Government has established several consultative bodies, such as the Council for Privatisation and Capital Projects, the Council for Co-operation with NGOs, and the Council for Improvement of Business Environment, Regulatory and Structural Reforms (Regulatory Council). The latter, for example, co-ordinates the activities of the state administration by analysing existing regulations in terms of business barriers and the need to simplify these regulations, initiates changes in regulation in the area of business environment, and agrees on establishing sub-working groups for specific topics (such as the plan to re-organise public administration) ${ }^{10}$. This body plays an important role in triggering and designing policy changes. Its members include the relevant ministers, senior civil servants, and representatives of business organisations, trade unions and municipal associations.

\section{Assessment}

The roles among the four key organisations in the CoG are well established and, in case of national policy making and co-ordination, there is sufficient clarity in responsibilities. Co-ordination among these four organisations happens often, based on the need to interact to fulfil certain common tasks. On a more

$8 \quad$ Also known as the Executive Council of the Government.

9 The Collegium includes the Prime Minister, Deputy Prime Ministers, Minister of Foreign Affairs and European Integration, and the Chief Negotiator.

10

Decision on Establishment of the Council for Regulatory Reform and Promotion of Business Environment, May 2012, updated with a new decision in January 2013 with an updated composition and a new name: the Council for Improvement of Business Environment, Regulatory and Structural Reforms. 
permanent basis, each of the central bodies tends to co-ordinate and interact primarily with the line ministries.

Regarding the overall El co-ordination, Montenegro has developed a dynamic and fairly decentralised framework, where the MFAEI provides political and administrative leadership on all El related processes, and the line ministries are responsible for analytical and preparatory tasks related to their specific policy areas. The Montenegrin negotiation structure includes: the Collegium, the Negotiating Team, the State Delegation for Negotiations, the working groups for negotiating chapters, the Office of the Chief Negotiator and the Secretariat of the Negotiating Team. This is a complex structure, adding to the existing co-ordination structures of the SAA.

When it comes to negotiating structure and the allocation of responsibilities, it could be said that political co-ordination of the process is concentrated in the highest negotiating body - the Collegium, which is the key forum for deciding the direction of negotiations. Since it consists of practically the same people as does the inner Cabinet, there is potentially strong co-ordination at the political level between El related policy directions and other government policies.

There are number of highly operational government advisory bodies (e.g. the Regulatory Council example above), but, due to the large number of them (73 in the beginning of 2013), the Government agreed in March 2013 to reduce their number and to encourage "decentralisation". This would be accomplished in such a way that, in the future, the Government would establish only those councils that could provide opinions and proposals with regard to the performance of its constitutional functions. At the same time, the councils and other bodies in charge of considering the issues falling under the competences of separate ministries would be established by the ministers. This is a necessary step to reduce the number of redundant advisory bodies while, based on the decision of the Government to maintain the most horizontal and relevant for the work of the Government (17 consultative bodies in total), keeping the necessary tools for co-ordination and regular dialogue with the key non-governmental stakeholders. This step should also enable better use of resources by the four co-ordinating organisations within the CoG. 
Table 1 summarises the key CoG functions and the established responsible institutions.

Table 1. Level of fulfilment of the nine key functions of the centre of government

\begin{tabular}{|c|c|c|}
\hline Key function of the CoG & Fulfilled in Montenegro & $\begin{array}{l}\text { Responsible } \\
\text { institution }\end{array}$ \\
\hline $\begin{array}{l}\text { Co-ordinating preparation of government } \\
\text { sessions }\end{array}$ & Yes & GSG \\
\hline Ensuring legal conformity & Yes & $\begin{array}{l}\text { Secretariat for } \\
\text { Legislation }\end{array}$ \\
\hline $\begin{array}{l}\text { Co-ordinating preparation and approval of the } \\
\text { government's strategic priorities and work } \\
\text { programme }\end{array}$ & Partly & GSG \\
\hline $\begin{array}{l}\text { Co-ordinating policy content of proposals for } \\
\text { government decision, including defining the } \\
\text { process of policy preparation and ensuring } \\
\text { coherence with government priorities }\end{array}$ & Partly & GSG, PMO \\
\hline $\begin{array}{l}\text { Ensuring policies are affordable and } \\
\text { co-ordinating planning of public sector resources }\end{array}$ & Yes & MoF \\
\hline $\begin{array}{l}\text { Co-ordinating government communication } \\
\text { activities to ensure the coherence of the } \\
\text { government message }\end{array}$ & Yes & GSG \\
\hline $\begin{array}{l}\text { Monitoring government performance to ensure } \\
\text { that the Government collectively performs } \\
\text { effectively and keeps its promises to the public }\end{array}$ & Partly & GSG \\
\hline $\begin{array}{l}\text { Handling relations between the Government and } \\
\text { other parts of the state (President, Parliament) }\end{array}$ & Yes & GSG \\
\hline Co-ordination of El affairs & Yes & MFAEI \\
\hline
\end{tabular}

Note: Prime Minister's Office (PMO).

Source: SIGMA.

Montenegro has allocated most of the key functions of the CoG, with some limitations in three out of the nine functions defined by SIGMA:

i) Co-ordinating and preparing government priorities and work programme are distinct in the preparations for the annual Government Work Programme, but there is no clear centre for co-ordinating strategic priorities at the administrative level. This does not mean that there is no co-ordination. On the contrary, as described in section 1.3, government strategic documents have a fair degree of consistency. Nevertheless, formal obligations and regular practice is not fully established in Montenegro for medium-term priority setting and work planning.

ii) For co-ordinating the policy content of proposals for decision by the Government, the GSG does not have the resources for substantial work, except by the advisory staff of the Prime Minister and the Deputy Prime Ministers.

iii) Today, monitoring progress in the work of the Government focusses on the fulfilment of activities under the annual Government Work Programme. Wider analysis of government work performance is not done centrally, although reports on the implementation of the Government's conclusions and on the work of ministries are prepared.

Compared with a number of more recent EU Member States, there are no major differences in the organisation of CoG work in Montenegro. As in other countries, the GSG (which is the government office) fulfils a number of key roles in planning and ensuring the quality of government work. The existence of a 
separate organisation (Secretariat for Legislation) for ensuring legal conformity is common among the countries of former Yugoslavia, but is not widespread among other EU Member States.

Table 2. Institutional solutions to provide extended centre of government functions in Montenegro and selected EU Member States

\begin{tabular}{|c|c|c|c|c|c|}
\hline Country & $\begin{array}{c}\text { Policy } \\
\text { co-ordination } \\
\text { unit }\end{array}$ & $\begin{array}{l}\text { Strategic } \\
\text { planning } \\
\text { unit }\end{array}$ & $\begin{array}{l}\text { Work } \\
\text { planning } \\
\text { unit }\end{array}$ & $\begin{array}{l}\text { Communications } \\
\text { co-ordination unit }\end{array}$ & $\begin{array}{c}\text { Impact } \\
\text { assessment } \\
\text { management unit }\end{array}$ \\
\hline Montenegro & $\begin{array}{l}\text { Some in } \\
\text { GSG/PMO }\end{array}$ & - & GSG (GO) & GSG (GO) & MoF \\
\hline Bulgaria & Some in PMO & - & GO & PMO & - \\
\hline $\begin{array}{l}\text { Czech } \\
\text { Republic }\end{array}$ & - & - & GO & - & - \\
\hline Estonia & $\mathrm{GO}$ & GO & $\mathrm{GO}$ & GO & - \\
\hline Hungary & $\mathrm{GO}$ & GO & GO & GO,PMO & GO \\
\hline Latvia & $\mathrm{GO}$ & GO & GO & GO & GO \\
\hline Lithuania & $\mathrm{GO}$ & GO & GO & GO & - \\
\hline Poland & GO/PMO & GO/PMO & GO/PMO & GO/PMO & GO/PMO \\
\hline Romania & No & No & $\mathrm{GO}$ & No & No \\
\hline Slovakia & No & No & GO & No & No \\
\hline Slovenia & No & No & GO & No & No \\
\hline
\end{tabular}

Note: Government Office (GO).

Source: SIGMA; Information for other countries collected in 2011; information for Montenegro collected in 2013.

Compared to a number of EU Member States, the CoG does not have a dedicated unit dealing with government strategic planning. In reality, these roles are partially fulfilled by the advisers of the Prime Minister and some Deputy Prime Ministers, and by the MoF in some instances. Policy co-ordination is also concentrated with the advisory staff of the Prime Minister.

\subsubsection{General Secretariat of the Government}

The GSG is governed by a special government decree that sets out its basic tasks to support the Prime Minister and the Government in preparing for their decisions.

In relation to policy co-ordination, the GSG is specifically assigned to: i) prepare the annual Government Work Programme; ii) co-ordinate relations with Parliament and the President; iii) prepare government sessions; iv) support the ministerial commissions; and v) ensure government communications. There is no direct assignment to co-ordinate government strategic planning or specific tasks to ensure coherence in government decisions.

The GSG has 123 employees (with around 182 foreseen in the latest Act on Internal Organisation and Systematisation of the General Secretariat. See Figure 1). In addition to the core tasks of supporting government decision making, the structure of the GSG includes sizeable departments dedicated to supporting the Deputy Prime Ministers and to working on special co-ordinating functions (e.g. co-operation with NGOs and representing Montenegro in the European Court of Human Rights). 
Figure 1. Staff positions foreseen in the systematisation of the GSG ${ }^{11}$

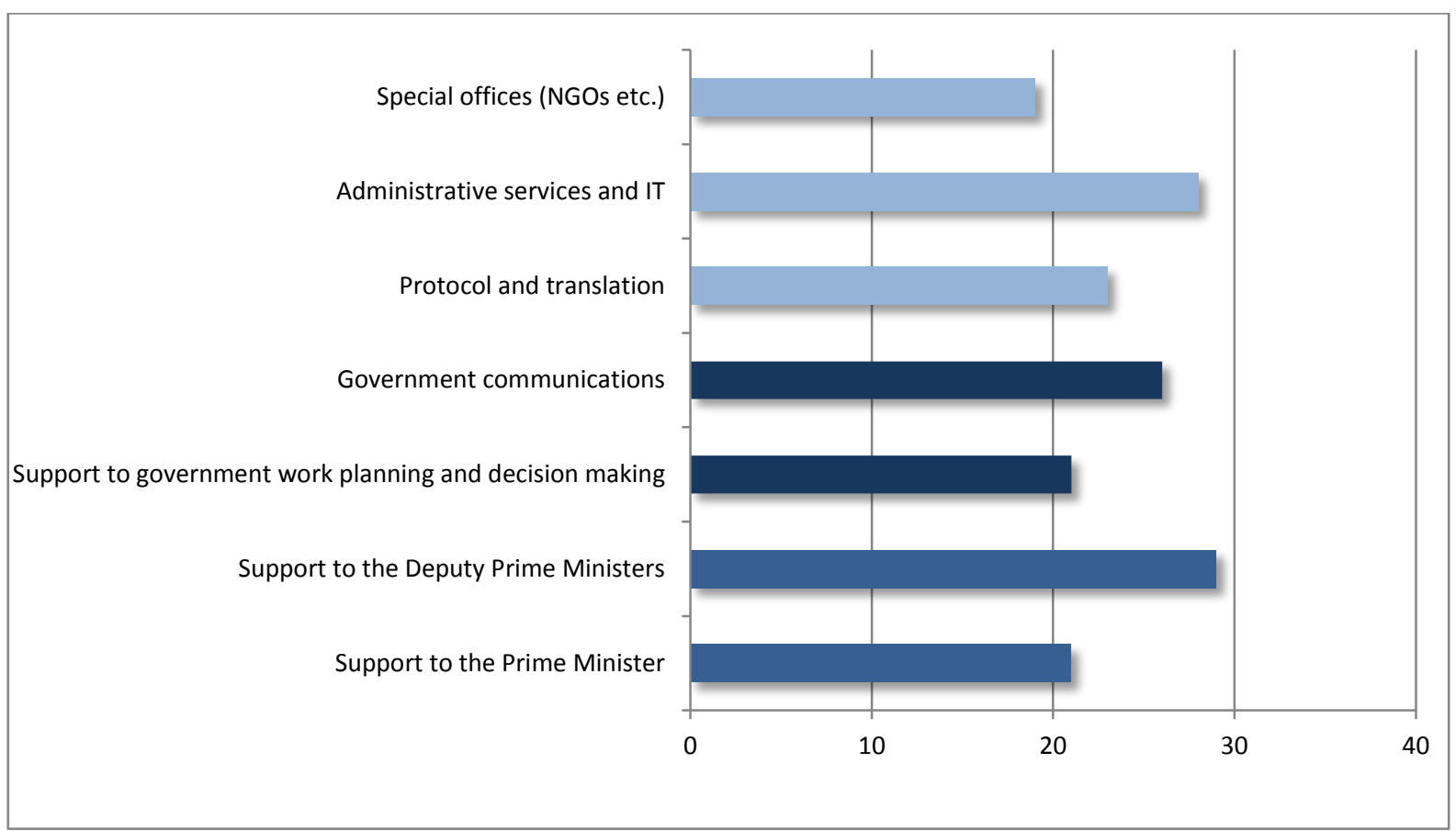

Source: Systematisation Act of the General Secretariat of the Government.

The GSG is comprised of several sectors. The Sector for Planning, Co-ordination and Monitoring of Implementation of Government Policy is responsible for ensuring the horizontal co-ordination and homogeneity of the annual Government Work Programme and the line ministries. It has five staff members, with two more foreseen under the new systematisation. In principle, the Act on Internal Organisation and Systematisation gives a mandate to work more widely with government strategic planning. In practice, the focus has been on annual planning and monitoring.

The Government Affairs Sector is responsible for organising government sessions, as well as the meetings of the permanent working bodies, including revision of draft material submitted for government decisions. It has 12 staff members, with 15 positions foreseen under the new systematisation.

The Public Relations services has more than 17 staff members, with 26 foreseen under the new systematisation. In addition to direct government public relations, they are also engaged with co-ordinating communications work across ministries.

The PMO is also well staffed and covers all the key policy areas of the Government. In addition to supporting the Prime Minister directly (e.g. writing briefs and speeches), it co-ordinates policy development of priority matters for the Prime Minister, being often involved in different working groups established by the Government.

The cabinets of Offices of Deputy Prime Ministers are relatively small, with two to four advisers and secretarial support. The Deputy Prime Ministers are also responsible for the work of a ministry, from which they get the main content support.

Today, GSG also houses three special offices: i) the Office for the Co-operation with the NGOs; ii) the Office for the Fight Against Trafficking in Human Beings; and iii) the Office of the Montenegrin Agent Before the European Court of Human Rights. These are placed within the GSG, but do not form a part of the core functions of a typical government office and thus could easily be part of any other state authority.

11 Data do not include support to the aviation service, which is a very specific function in the Government. 


\section{Assessment}

The GSG is relatively well staffed with its 123 current employees. The staff capacities for Public Relations services and direct support services for the Prime Minister and the Deputy Ministers are notably sizeable. The protocol and administrative services and the special offices also have rather high staffing levels in the overall context of Montenegro's central government.

Compared to a number of government offices in the EU, the GSG has not taken any substantial policy co-ordination roles, besides the annual Government Work Programme. In the case of Montenegro, the other cross-cutting strategic documents (e.g. the Development Directions of Montenegro, the Pre-Accession Economic Programme and the Strategy for Sustainable Development) are all co-ordinated by the ministries, with some involvement by the offices of the Prime Minister and Deputy Prime Ministers.

As a rule, the GSG is not involved in early preparation stages of policy documents and key legal drafts by the ministries. This is done only indirectly, through its contribution to the annual Government Work Programme. Ministries sometimes invite GSG employees into the working groups for specific policy initiatives, but their participation is exceptional and is based on the nature of the legal draft being prepared.

The staff capacity for regular policy co-ordination and strategic planning (the Sector for Planning, Co-ordination and Monitoring of Implementation of Government Policy) is perhaps the only area where it is reasonable to plan staff increases in the medium term. The resource for more expert staff for these currently underdeveloped functions could in the medium- and long-term be sought from the existing structures.

\subsubsection{Secretariat for Legislation}

The Secretariat for Legislation is an independent organisation supporting the Government with a legal oversight function. It acts upon its independent function, but is under the loose supervision of the GSG. It is primarily responsible for: i) monitoring and improving the legal system of Montenegro; ii) checking the compliance of laws and regulations with the Constitution and the legal system during preparation; iii) preparing specific regulations and general acts which are not the responsibility of ministries and other administrative bodies; and iv) giving opinions on draft laws and other regulations. The Secretariat for Legislation also takes care of releasing regulations, decisions and other acts of the Government, the laws and other policy acts ${ }^{12}$. It exercises supervision over the legality of the public institution Official Gazette of Montenegro.

The Secretariat for Legislation employs 19 people (of whom 15 are lawyers). They are organised in four thematic sectors. Most of the resources are tasked with reviewing legal acts before they are presented for government decision. In 2012, the secretariat worked with 735 cases in total, of which 100 were laws and 635 were by-laws and other acts with legal power. Most of these cases are reviewed at a late stage of law drafting, when the draft legislation is sent to the official interministerial consultation.

As for EU accession-related regulation, the MFAEI is in charge of harmonising with the acquis. They check if the meaning of the EU regulation is well transposed. The role of the Secretariat for Legislation is to check if the law is clear and fits into the national legal system.

\section{Assessment}

Since the Secretariat for Legislation gives opinions to all legal acts before their finalisation (including government decrees and by-laws approved by the ministers), the workload is occasionally very high. With a total staff of 19 , there is no leave room for proper dialogue with the ministries, and the secretariat staff cannot participate in the respective working group meetings from the early phases of law drafting.

Although the senior civil servants (including the Secretary) all have notable years of experience and their knowledge of the legal order of Montenegro noticeably exceeds the average level within the ministries, the current staffing levels are remarkably low compared with the responsibility to review all laws and

12 Article 35 of the Government Decree on Organisation and Manner of Operation of the State Administration. 
by-laws. If ministries had dedicated expertise on legal drafting, the existing organisation of the Secretariat for Legislation could be sufficient; but, in the current situation, the secretariat cannot perform some of its other functions, such as assisting in the process of preparing legislation and other regulations in accordance with the legal and technical rules for law drafting. Ensuring that consolidated texts of government regulations are systematically made public could also be enhanced over time.

The effectiveness of the Secretariat for Legislation depends largely on the capacities for policy drafting in the ministries. However, with the exception of some capacity building activities, such as contributing to training programmes, the secretariat has not taken on the responsibility of devising systematic steps for improving the quality of that work by the ministries.

\subsubsection{Ministry of Finance}

In Montenegro, three types of fiscal planning documents are prepared each year: i) the Guidelines for Macroeconomic and Fiscal Policy; ii) the annual budget; and iii) the Pre-Accession Economic Programme. The first is prepared each April and represents a framework document on the basis of which annual budget preparations start. It contains macroeconomic and fiscal revenue projections for the current and following three years, and the key economic policy orientations of the Government. For public finances, it primarily includes analysis of recent fiscal performance and mid-term projections of main fiscal indicators. The Pre-Accession Economic Programme is a fiscal and economic policy document that mirrors the content of Stability/Convergence Programmes and National Reform Programmes of the EU Member States.

The MoF is involved in policy co-ordination primarily by co-ordinating the mentioned fiscal policy documents and by developing the framework for RIA. Three sectors are mostly involved: i) the Sector for Economic Policy and Development (macroeconomic estimations, co-ordination of structural reforms and some key economic policy plans, such as the Development Directions of Montenegro); ii) the Sector for Financial System and Improvement of Business Environment (the Secretariat for the Regulatory Council and quality control over RIA documents); and iii) the Sector for Budget (budget preparation and quality control of fiscal impact analyses of policy proposals).

In the process of developing new policy documents, including legal acts, the MoF safeguards that the RIA is properly carried out. While the Sector for Financial System and Improvement of Business Environment has overall responsibility for quality control and advice to the ministries, the Sector for Budget contributes by reviewing the estimates on public revenues and expenditure. The process is often handled in an informal manner and only in exceptional cases does the MoF sends negative opinions formally to line ministries and other state organisations.

When working with the cross-cutting economic and fiscal policy documents, such as the Pre-Accession Economic Programme, the MoF liaises with the line ministries primarily on matters that concern the specific policy areas of other ministries. With the offices of the Prime Minister and responsible Deputy Prime Ministers, the liaison is more regular. There is no substantial co-ordination with the other parts of the GSG.

\section{Assessment}

The minimum working procedures and instruments exist within the MoF to ensure that policy planning takes into account financial limits. In general, the MoF staff have a solid understanding of their roles and responsibilities. However, their effectiveness is partly hampered, since the framework for ensuring that policy decisions are fed properly into budget planning is not as developed and many sectoral commitments are not analysed sufficiently in substance for a proper estimation on budgetary impacts. The MoF does take part in developing sector strategies and substantial draft laws, but the links between policy plans and budget proposals of the line ministries are still not entirely systematic.

The review of 2012 data concerning checking budgetary cost estimates of the RIA documents shows that the workload within the Sector for Budget varies greatly, depending on the internal responsibilities for certain ministries. The workload ranged from eight opinions during the year for the person covering the Ministry of Justice and the Ministry of Human and Minority Rights to over 100 opinions for the person 
covering the Ministry of Economy and Ministry of Sustainable Development and Tourism. This illustrates some of the reasons behind a rather loose quality filter by the MoF when new policy proposals (including draft laws) are consulted with the MoF.

It is commendable that, in the Sector for Budget, persons responsible for analysing fiscal impact estimations are the same as those responsible for analysing budget requests by the respective line ministries. However, in the MoF, two sectors are dealing with financial estimations: the Sector for Economic Policy and Development, and the Sector for Budget. In essence, both sectors have the need to develop similar sector knowledge for performing their specific tasks. In the current structure, it is advisable to encourage flexible teams across departments dedicated to certain wider sectors.

\subsubsection{Ministry of Foreign Affairs and European Integration}

The Government Decree on Organisation and Manner of Operation of the State Administration ${ }^{13}$ gives the MFAEI the overall leadership to co-ordinate Montenegro's EU accession process. The functions of the ministry are fivefold: i) lead the work of the established horizontal interministerial co-ordination structures; ii) initiate and prepare the strategies and working plans to be adopted by the Government, monitor their implementation and, through the horizontal interministerial co-ordination structures, report on progress; iii) co-ordinate the co-operation of government bodies with EU institutions; iv) co-ordinate the tasks of the harmonisation of national legislation with the acquis, including ensuring compliance and translation of the acquis; and v) programme, evaluate and monitor technical and financial assistance (including the IPA).

The Directorate General for European Affairs (DGEA) and the MFAEI in general, as the centre of Montenegrin EU accession-related co-ordination efforts, have developed specialised structures to fulfil their functions. Currently, the DGEA is divided into three directorates which together employ around 32 people: 18 working for the Directorate for EU Accession, six for the Directorate for Translation and six for the Directorate for Legal Harmonisation. Under the new systematisation, the DGEA will have three functional divisions (directorates) and a foreseen staff of 39.

Table 3. Structure and required capacities of the Directorate General for European Affairs under the existing systematisation

\begin{tabular}{|c|c|c|c|c|c|c|c|}
\hline \multirow[b]{2}{*}{ Structural units } & \multirow[b]{2}{*}{ 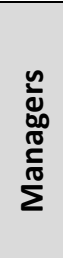 } & \multicolumn{4}{|c|}{ Administrators } & \multirow[b]{2}{*}{ 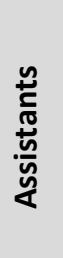 } & \multirow[b]{2}{*}{ 胥 } \\
\hline & & 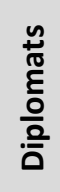 & 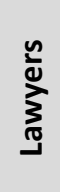 & 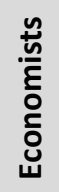 & 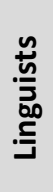 & & \\
\hline Directorate General & 1 & & & & & 1 & 2 \\
\hline Directorate for EU Accession & 1 & & & & & & 1 \\
\hline $\begin{array}{r}\text { Department for Political } \\
\text { Criteria }\end{array}$ & 1 & 6 & & & & & 7 \\
\hline $\begin{array}{r}\text { Department for Economic } \\
\text { and Financial Criteria }\end{array}$ & 1 & 7 & & & & & 8 \\
\hline Department for Sector Policy & 1 & 6 & & & & & 7 \\
\hline $\begin{array}{l}\text { Directorate for Legal } \\
\text { Harmonisation }\end{array}$ & 1 & 5 & & & & & 6 \\
\hline Directorate for Translation & 1 & 1 & & & 5 & 1 & 8 \\
\hline Total & 7 & 25 & 0 & 0 & 5 & 2 & 39 \\
\hline
\end{tabular}

Source: Systematisation Act of the Ministry of Foreign Affairs and European Integration. 
As regards the co-ordination centre, the DGEA leads and manages the co-ordination activities specifically related to the SAA process and partly also to the overall El process, thus performing the tasks of the central co-ordination unit. Currently, the DGEA's ability to be in touch with the work done by the negotiation working groups is ensured through Secretaries of Working Groups, nominated from within the MFAEI (mostly from the DGEA).

The second Directorate General that plays a role in policy co-ordination is the Directorate General for Co-ordination of the EU Assistance Programmes. It fulfils the functions of the NIPAC, as well as acts as the operating structure for EU-funded cross-border co-operation programmes. Through their role is specifically to co-ordinate the plans for IPA funds, NIPAC secretariat in fact also supports the EU accession process by facilitating resource planning. The State Secretary fulfils the roles of both NIPAC and Chief Negotiator. The Directorate General for Co-ordination of the EU Assistance Programmes has foreseen, in total, 21 positions under the most recent systematisation.

\section{Assessment}

As regards the centre of co-ordination for El, the DGEA's ability monitor, mediate and give input into political decision making level on all levels of the process is crucial. The current format, where the Chief Negotiator is also State Secretary, is commendable, as this arrangement ensures that there is a direct link between the DGEA and the political decision making level both within the ministry and in the highest political (i.e. Prime Minister) levels. Since the State Secretary also fulfils the role of NIPAC, there is potentially a good basis for linking El planning with EU-funded projects.

Nevertheless, there are possible weaknesses. One is the risk of fragmentation of the core co-ordination functions of the MFAEI. The decision to establish an Office for the Chief Negotiator separate from the DGEA raises certain questions. First, the Office for the Chief Negotiator requires highly skilled policy co-ordinators, advisers and diplomats in order to fulfil its functions. These skills are also needed in the DGEA. Second, there is a possibility that the office, being closer to the Chief Negotiator, might be better informed about substantial discussions than the DGEA, which cannot fulfil its functions as the operational centre for co-ordination effectively if it is left out of information flows. As the preparatory work done for the Chief Negotiator largely corresponds to the functions carried out by the DGEA, there is a clear case for aligning their functions. The new organisational set-up has nevertheless worked well for the time being and urgent changes are not needed.

Regarding the DGEA's ability to function as an actual centre of co-ordination for the overall El process, another potential problem is the current perception of the line ministries. Ministries tend to see the DGEA's technical functions in organising meetings as its primary utility and value. This limited appreciation of the DGEA's role may be understandable in light of the only recent changes in overall co-ordination. Also, in practice, the DGEA, in co-ordination with the Office for the Chief Negotiator, enters into substantial policy matters. However, these aspects may become problematic once the process needs a more decisive co-ordination effort and stronger and even more substance-oriented leadership.

In addition, smaller aspects of the new systematisation may merit a second look during future revisions of this document. For example, qualifications for some foreseen staff requirements may be unnecessarily ambitious and restrictive. Administrators within the Directorate for Legal Harmonisation have to pass diplomatic consular exams, but the job requirements do not mention any need for law school education or knowledge of the EU legal order. More generally, good policy co-ordinators are essentially skilled middle- or low-level managers who do not necessarily have to be diplomats. Imposing requirements for prospective officials to have three to five years relevant experience of the process might be equally unjustified when the process has only just started. This requirement may hamper recruitment of viable candidates who have experience in co-ordinating large-scale projects, but who could not have obtained experience in the El process. Leading and managing national processes is essentially a universal skill, which can be applied to all policy fields. Relevant El knowledge should not be given priority over good managerial skills.

The MFAEI has a reasonable level of staff to co-ordinate IPA planning, if not fully to the levels foreseen in the new systematisation. NIPAC's position in the MFAEI allows for functions as regards the European Commission and the line ministries of Montenegro. While IPA funds are mostly supporting the EU 
accession agenda, the current location of the NIPAC office is the most suitable option. Closer to EU membership, the Government would need to consider where this central planning function is best placed to support overall government economic and social policy objectives.

In general, there is a good vision for preparing the Montenegrin EU funds management system for Cohesion Policy funding after potential EU membership. The main weakness in IPA planning is that it is not systematically embedded into regular sector-based policy planning, although some ministries are taking this responsibility to link IPA resources with their overall medium-term policy plans more seriously. Donor co-ordination in general is not well organised at the central level, although the donor community itself has been able to share most of the critical information for assistance planning.

\subsection{Main horizontal policy making processes}

The CoG should have the capacity to perform the tasks related to overall management of the policy system, as well as actual capacity and authority (legal, personal and professional) to design, implement and enforce the provisions of the legal framework. This section of the review analyses three specific work streams of the Government in more detail.

\subsubsection{Co-ordination of the Government's strategic priorities, annual Government Work Programme and budget}

According to the RoP, the Government approves an annual Government Work Programme by the end of December for the following calendar year. The programme is prepared in accordance with the guidelines and instructions issued by the GSG, and it is considered the principal planning document of the Government. The GSG has a role in clarifying the priorities of the Government as an input into the preparation of the programme.

The annual Government Work Programme covers draft laws, strategies, action plans, information on state of affairs in specific areas of government competencies and other key documents for the decisions of the Government. It also establishes basic data, responsible ministers and quarterly deadlines for its implementation. There is no effective costing or link to budget within the programme, but when the planned activities (e.g. drafting of laws) are brought to the Government, a more detailed RIA is presented with the draft legislation or strategy.

The GSG prepares the annual Government Work Programme based on ministry proposals. Prior to the government session, the draft is delivered to government commissions for consideration within the scope of their work. On the basis of commission proposals and suggestions, the GSG prepares a final draft of the annual Government Work Programme for proposition. The GSG also monitors implementation of the annual Government Work Programme and prepares and delivers quarterly and annual reports on implementation to the Government.

Multi-annual planning occurs through sector-specific strategies and a few horizontal policy documents, such as the Development Directions of Montenegro or the Pre-Accession Economic Programme, and, from the beginning of 2014, through the Programme of Accession of Montenegro. There are no specific requirements for sector strategies.

\section{Assessment}

There is a good system in place for preparing the annual Government Work Programme. There is a visible link between the annual work-planning process and the strategic priorities of the current Government. The annual Government Work Programme is compiled with both bottom-up and top-down input. The GSG takes an active role in drafting the annual Government Work Programme by guiding ministries as they prepare their input to the programme, ensuring that they take into consideration the strategic priorities of the Government and do not include items that should be handled by the relevant minister. Planning for the 2013 Government Work Programme had begun already at the level of civil servants before the October 2012 elections.

The GSG itself provides meaningful input into the annual Government Work Programme, i.e. it does more than just staple together ministry proposals. It has some authority to influence what is included in the 
programme (add and remove items) when it disagrees with ministries. For example, the annual Government Work Programme for 2013 had close to 500 proposals, of which slightly more than half remained in the final document.

Recent practice demonstrates reasonable discipline in meeting programme deadlines.

Figure 2. Overview of ministries meeting their commitments in the annual Government Work Programme

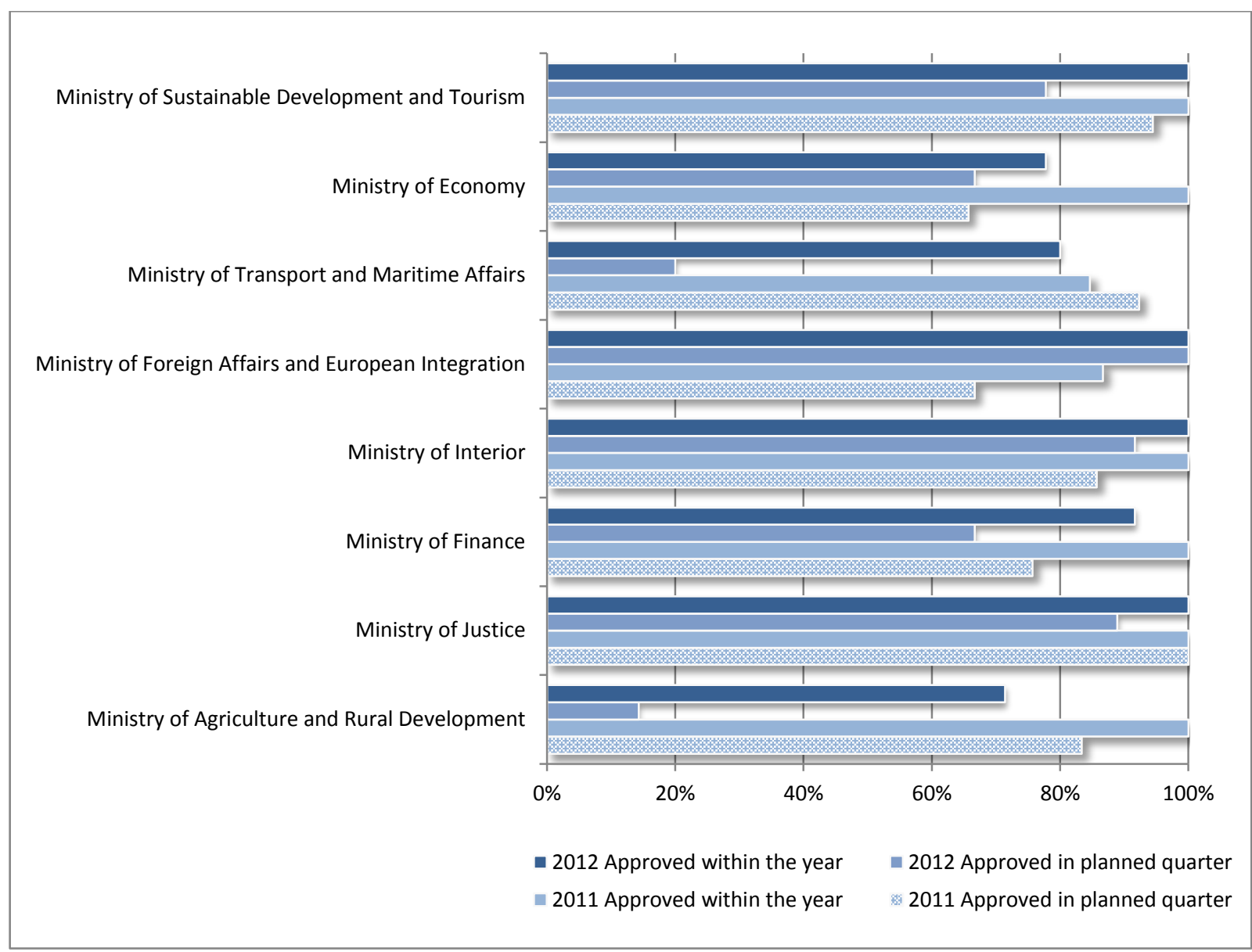

Source: annual General Secretariat of the Government monitoring reports of the implementation of the annual Government Work Programme.

The GSG's quarterly and annual monitoring reports do not distinguish between the process implementation and implementation in reality; they do not evaluate the final outcomes of the implementation of policies. On the contrary, they are quantitative, listing the number of documents whose adoption was planned in the time period and the number of documents which were actually adopted. Co-operation with the MoF in preparing the annual Government Work Programme is not particularly developed, partly because the programme primarily includes administrative activities that are not costly themselves.

The main weakness of the horizontal strategic planning system in Montenegro is the lack of a systemic approach in medium-term policy planning. Government priorities are announced without specific measures or deadlines, and elements for medium-term budgetary planning are represented only in the draft Law on Budget and Fiscal Responsibility, which has yet to be adopted by Parliament ${ }^{14}$. The main horizontal policy document for El affairs ${ }^{15}$ was outdated until the end of 2013 when a new strategy - the

14 The draft Law on Budget and Fiscal Responsibility is in its final stages of decision making, having been approved by the Government and sent to Parliament.

$15 \quad$ National Programme for Integration 20082012. 
Programme of Accession of Montenegro - was developed. The situation is clearer in economic policy co-ordination, where the Government has adopted concise horizontal planning documents ${ }^{16}$.

In order to evaluate the overall coherence of key policy planning instruments, SIGMA reviewed and compared the following strategic documents: i) the Prime Minister's address to Parliament, 4 December 2012, on the four year priorities of the Government; ii) the 2013 annual Government Work Programme; iii) the Pre Accession Economic Programme 2012 2014; iv) the Development Directions of Montenegro 2013 2016; and iv) the 2013 priorities of the Regulatory Council. The review focussed primarily on planning for 2013. Direct comparison (e.g. in the form of a table) is not feasible in this case, as all of these programmes has specific scopes and mandates.

Overall, there was a fair degree of consistency among the above strategic plans. Although the four year priorities are only available via the Prime Minister's address in Parliament, the 2013 annual Government Work Programme reflects the announced priorities, as do the structural reforms and measures in both the Pre-Accession Economic Programme and the Development Directions of Montenegro. The Regulatory Council's four priorities for improving the business environment are directly aligned with World Bank indicators and are also reflected in the Development Directions of Montenegro.

There is no comprehensive, government-wide public progress report. Representatives of the GSG indicated such a report isn't feasible, due in part to the high number of sectoral strategies ${ }^{17}$ which are themselves not part of a tangible strategic planning framework. Their scope, information and overall quality vary.

Another systematic weakness in policy co-ordination is the GSG's lack of capacity to review draft policies for coherence with previous commitments and priorities. The PMO fulfils this role in part, but not systemically as regards analysing sector strategies and other planning documents.

Ensuring coherence between budgeting and policy development is weak for several reasons. First, not all sector strategies have realistic financial estimations. Second, the budget process does not require ministries to demonstrate strong links between existing strategies and budget proposals. Third, co-ordination of donor funding (including IPA) is handled by the MFAEI. While there is some information exchange between the MoF and MFAEl, the link between certain priorities and funding is more visible in IPA funding planning. Fourth, recent fiscal policy is focussed on reducing public expenditure, providing less funds for new policy priorities.

During budget formulation, there is no procedure for considering strategic acts currently in force. Furthermore, budgeting is focussed solely on the next fiscal year, limiting incentives to estimate medium-term financial needs, and there are no real multi-annual budget planning procedures in place for line ministries. A number of horizontal elements of fiscal policy planning are present in the Pre-Accession Economic Programme and the Economic Policy Guidelines, but these do not provide incentives for ministries to align their own capacities for financial planning. The situation is somewhat better in practice; informal co-ordination within and among most ministries generally works well. Pragmatic solutions ensure attention to budgetary constraints, including effective controls in capping budget execution in central government.

From the side of policy preparation, procedures for linking planning with annual and medium-term financial planning are also under-developed. There is an obligation to prepare budgetary impact estimations in RIA reports (see part 2 of this review), but sector policy planning beyond annual work plans is otherwise not centrally guided. Ministry strategic plans often include budget estimates, but usually this information is not fully debated or met in practice.

\subsubsection{Co-ordination of European integration plans and strategies}

The co-ordination structures of the Government for EU accession negotiations, as established in 2013, include: 
i) A Collegium for Negotiation, which functions as the main political centre of co-ordination. It is also the de facto forum to evaluate and discuss various policy options, as government sessions are largely only a formal setting where decisions are adopted. The Collegium consists of the Prime Minister, the Deputy Prime Ministers (among whom is the Minister for the MFAEI) and the Chief Negotiator.

ii) The Negotiation Delegation, headed by the Minister for the MFAEI, which conducts high-level negotiations with the EU.

iii) The Chief Negotiator and his or her Office, which supports the fulfilment of his or her tasks.

iv) The Negotiating Team, consisting of the Chief Negotiator, heads of working groups and its secretariat (in reality, the DGEA of the MFAEI), which negotiates with the EU on a technical level and reviews draft negotiation positions.

v) The working groups and their heads and secretaries for each negotiation chapter, which conduct screening and prepare draft negotiation positions.

In Montenegro, the Commission for European Integration was established in May 2012, together with seven working groups mirroring the SAA sub-committees and 35 sub-working groups according to negotiation chapters. The task of the commission, which is not fully a new forum, is to assess and prepare all government decisions on the El process and to monitor and report the fulfilment of SAA action plans. The working groups and sub-groups prepare the necessary items at each sector at the technical level. In early 2013 the role of the commission was transformed to oversee the Programme of Accession.

The co-ordination system now has two structurally separate interministerial horizontal layers - for the SAA and EU accession process, respectively - set up to steer El-related work. Line ministries report quarterly through both systems via quarterly reports on implementation of the SAA, reports on the stabilisation and association process and input to the Government's Progress Reports for the European Commission. The interministerial layers, in particular the Commission for European Integration, are intended both for drafting Action Plans and for monitoring. In practice, most necessary data can be collected via a specialised portal for El.

Until the end of 2013, there was no single framework document to plan and co-ordinate the EU accession process over the medium-term. European integration-related tasks were planned into the annual Government Work Programme or on an ad hoc needs basis, e.g. separate action plans to meet accession negotiation benchmarks. The Government has finished the preparations for a new National Programme of Accession (NPA): the Programme of Accession of Montenegro 20142018 is a rolling planning document covering information by negotiation chapters, including strategies in the sector, legislative framework and administrative capacity.

\section{Assessment}

The co-ordination system has a complex architecture. It is also far from fully set, primarily due to the start of a new phase of the EU accession process. Ministries have to report through several processes and this makes the reporting system cumbersome and time consuming. Reporting obligations add up and increase the administrative burden of the ministries. There is an opportunity to streamline planning, prioritisation and reporting under the next update of the Programme of Accession of Montenegro 20142018.

Strategic management and monitoring require a defined roadmap with at least five functions:

i) Prioritise and instruct: assign tasks to ministries and agencies to progress with enlargement, including an outline of priorities, actions, responsibilities and how implementation will be measured.

ii) Serve as a negotiation document towards the EU, transmitting information about the candidate country's intentions and achievements.

iii) Provide the basis for the strategic use of pre-accession assistance and national budget resources for EU accession purposes. 
Act as a monitoring tool.

v) Inform stakeholders, social partners, sub-national levels of government and the public on activity.

Table 4 summarises the potential of the current NPA to fulfil the above functions.

Table 4. Potential of National Programme of Accession to fulfil strategic functions

\begin{tabular}{|l|c|}
\hline \multicolumn{1}{|c|}{ Function } & $\begin{array}{c}\text { Potential to fulfil/Likely use } \\
(5=\text { highest probability })\end{array}$ \\
\hline Prioritise and instruct & 4 \\
\hline Negotiation document & 3 \\
\hline Strategic use of assistance & 5 \\
\hline Monitoring tool & 2 \\
\hline Information sharing & 3 \\
\hline
\end{tabular}

Source: SIGMA report "Analysis of the plans for the Programme of Accession of Montenegro: focus on administrative capacities".

Although there is now a medium-term framework strategy for EU accession (the NPA), there is an increasing problem of prioritisation in allocating resources. With the current planning framework, the accession-related tasks are still split among negotiation chapters, making it difficult to prioritise accession-related actions in budgetary negotiations. The Programme of Accession of Montenegro 2014 2018 is nevertheless useful to capture all the different commitments and the MFAEI can use it to monitor the work of the ministries in sufficient detail. Future updates of the Programme of Accession of Montenegro would deserve further attention to horizontal aspects of El, including the capacities of the MFAEI itself to function as a central co-ordinator of European policy affairs after accession.

In reality, interministerial co-ordination is done on an ad hoc basis. Although participants see the value of formal structures, most day-to-day problems are solved bilaterally through informal networks and contacts. Those co-ordinating the association process (Commission for European Integration) or the EU accession process (Negotiation Team) are often the same people, but not always. Moreover, those in charge of accession negotiations within ministries are mostly general directors who occasionally outrank those in charge of the association effort. Where the functions of managing association and accession processes do not match, additional co-ordination practices and/or streamlining the two interministerial co-ordination layers currently operating in parallel is needed.

Staff expertise for the work done by the Directorate for Legal Harmonisation is considered high. The core civil servants have been in the post since the start of the El process, and have developed invaluable knowledge, not only of the acquis, but crucially of its relationship with the Montenegrin legal order. However, the directorate has limited capacity with only five lawyers while their workload can be expected to grow. Also clear is an anticipated need for and development of real expertise of the acquis within the respective line ministries.

While necessary, horizontal legal oversight is currently performed from within both the Secretariat for Legislation and the MFAEI, respecting their expertise. This may lead to rare situations where opinions are seen by the ministries to contradict wholly or in part. Furthermore, in practice there is no single authority in charge for supporting capacity building within ministries. The Directorate for Legal Harmonisation and the Legal Secretariat could join resources for more systematic capacity building support for the ministries, ensuring consistent co-ordination and exchange of views between the two horizontal bodies, and mitigating conflicting signals.

In the medium term, a similar review could be useful regarding the fulfilment of the functions of the MFAEI concerning IPA financing. This will become more relevant once the primary focus of EU funds will move increasingly from acquis-related actions to overall economic development. Budgetary planning 
should in principle encompass all resources under the Government's control. If the MFAEI retains its co-ordinating role for IPA funds, the smooth co-operation between the MFAEI and the MoF must be ensured in order that IPA funding, which is so far used for short-term projects, may be complemented by the long-term budgetary resources from the state budget. As the pace of the El process is more and more determined by progress in implementation, the lack of resources or gaps in budgetary plans could seriously hamper it.

Although the term "negotiation process" implies that the bulk of the work ahead lays between the EU and Montenegrin authorities, as past EU accession negotiations demonstrate, it is in fact domestic; the really hard negotiations are internal. The central co-ordinating authority needs to mediate and co-ordinate the views of the various domestic interest groups and actors. This requires a well carved place within the CoG hierarchy and the 'tools' to ensure that an institution has the ability to 'push other institutions into action'. However, such tools need to be aligned with, or at least not diverge widely from, the general architecture of the Government, as defined by the legal framework. At present, the political constellation favours the role of the MFAEI in this regard.

\subsubsection{Co-ordination, preparation and communication of government sessions}

Government decision making is channelled through its formal weekly sessions. The RoP describe the main steps in decision making, including the roles of different working bodies, and establish procedures and requirements for submitted materials and consultation. The weekly schedule leading to the government session is as follows:

- Monday - meeting of the inner Cabinet, comprised of the Prime Minister, Deputy Prime Ministers and Secretary General. Other ministers are invited to take part in the work of the inner Cabinet as needed. Inner Cabinet meetings are less formal than other regular meetings of government members.

- Tuesday - meetings of the permanent working bodies of the Government: thematic government commissions that review the material submitted for government decision.

- Thursday - formal sessions where government decisions are taken.

According to the RoP, draft laws and proposals for strategic plans are submitted at least 15 days before the targeted government session. In reality, laws and strategies also arrive to the GSG later and are still decided by the Government. As a rule, material received by the previous Thursday is placed on the commissions' agenda for Tuesdays. There is also a formal procedure to enable consideration of urgent issues at a government session ${ }^{18}$ that allows the Prime Minister to convene a special session of the Government or allows a member of the Government to propose amendments to the agenda.

The GSG verifies that materials submitted to the Government are prepared according to the RoP. The GSG can return items to the ministries if the substance is problematic or formal requirements are not fulfilled (e.g. the proposal does not contain the opinion of the MoF or Secretariat for Legislation, or if it is not in line with the activity envisaged in the annual Government Work Programme). In practice, the GSG resolves most outstanding issues informally, consulting the proposing ministries and requesting additions or clarification rather than returning full documentation. In exceptional cases, they have sent the material to the relevant commission without all required documents.

European integration issues and legislation needed for transposing the acquis follows the same procedure as all government agenda items. However, the MFAEI is responsible for providing opinion on harmonisation with the acquis.

The Government has established four thematic commissions, of which the Commission for Political System, Internal and Foreign Policy ${ }^{19}$ and the Commission for Economic Policy and Financial System ${ }^{20}$ form

\footnotetext{
18 Articles 50 and 55 of the Rules of Procedure of the Government.

19 Article 15 of the Rules of Procedure of the Government.

20 Article 16 of the Rules of Procedure of the Government.
} 
the more relevant parts of the government decision making system for new policy proposals ${ }^{21}$. These commissions act primarily as filters to make sure that the content of the policy proposals is in line with the wider government policy and that only mature proposals are presented for a formal government decision.

The agenda of government sessions has several parts: i) items prepared according to the annual Government Work Programme; ii) material prepared according to ongoing government activities; iii) materials submitted for government verification; iv) material submitted for government opinion or consent; v) other ongoing issues; and vi) material submitted for governments insight ${ }^{22}$.

The GSG internal working procedures are not established in detail. There are no specific requirements for preparing the Prime Minister for government sessions (e.g. provision of briefing notes). Also, there are no specific rules governing internal co-ordination in preparing government sessions (e.g. meetings of the General Secretary with the head of the PMO or regular management meetings within the GSG). The General Secretary of the Government and Secretary of the Secretariat for Legislation attend government sessions and have the right to take part in the work of the Government.

Although most conflicting views among ministries are resolved before material is submitted to the GSG, there is a clear procedure to resolve any disagreement before proposal ${ }^{23}$ The final content of the law and other proposals which previously failed to comply with the opinions of the Legislation Secretariat and competent ministries cannot be incorporated into the agenda of a government session until the disputed issues are agreed with the competent Deputy Prime Minister. In practice, this is also done during the meetings of the relevant commissions.

After the Government has taken a decision on a proposal, the drafting ministry has one week to submit final documents with the wording approved by the Government to the Secretariat for Legislation and further to the $\mathrm{GSG}^{24}$.

The majority of material considered at the government session is published on the Government's website, including proposed agenda of the government session, materials to be discussed by the Government which are not subject to confidentiality rules, and verified conclusions of the Government ${ }^{25}$.

The Government organises regular press conferences to inform the public about their decisions. Press statements from government sessions are normally given by the Deputy Prime Ministers along with ministers appointed by the Prime Minister. Communication with the public and the media is handled jointly by the PMO and the dedicated department in the GSG: the Bureau for Public Relations.

The GSG has co-ordinated a network of PR and communications staff within the line ministries, which met, as a rule, once a week. Along with the regular updates of communications issues in the ministries, the network has also developed procedures to enable better public relations work. One example is a template that ministries proposing new policies fill in to better equip communications officers to deliver the critical substance to the public.

Assessment

The overall co-ordination of government sessions ensures the involvement of key stakeholders and enables input from both the political and administrative levels, as well as sufficient time for processing material. Occasionally, regular timetables are not respected and exceptional consultation procedures are used when urgent decision making is not strictly warranted ${ }^{26}$.

21 The two other working bodies are the Commission for Human Resources and Administrative Issues and the Commission for Distributing a Part of Budget Reserve.

22 Government session agenda on 14 February 2013.

23 Article 42 of the Rules of Procedure of the Government.

24 Article 65 of the Rules of Procedure of the Government.

25 Article 2 of the Decision on publishing materials from sessions of the Government of Montenegro.

26 For example, the case of substantial amendments to the Law on State Administration where urgent procedure was motivated by the need to harmonise with the acquis. 
After policy proposals, including draft laws, are cleared by the ministries and other state authorities, the decision making process is straightforward and implemented with a high degree of consistency. The roles of different working bodies and the GSG are clearly regulated and the interviews carried out did not reveal any major confusion in who does what at the late stages of preparations for government decisions.

The GSG has sufficient authority to handle material submitted by ministries, including returning incomplete material. Secretaries of working bodies in the Government Affairs Sector systematically analyse the policy content of draft proposals, but they would not challenge the proposing ministry on substance. The PMO and the offices of the Deputy Prime Ministers are currently better placed in following and reviewing the content of the policy proposals.

The 15-day-prior submission deadline may be too restrictive for ministries, given a comparatively small administration with many issues requiring rapid government response. It is therefore often not followed. At the same time, adherence to preceding procedures for interministerial and stakeholder consultations is important. In that case, a shorter submission deadline could be considered.

Compared to many EU member countries, dialogue between ministries and conflict resolution at the final stages of decision making is almost exclusively in the hands of political leaders, the Deputy Prime Ministers in particular. The final steps of decision making do not include regular forums with the highest civil servants of ministries; only the General Secretary of the Government, the Secretary of the Secretariat for Legislation and, in some cases, the Chief Negotiator for EU accession have regular opportunity to discuss at the weekly meetings.

Preparing final texts after decision is somewhat cumbersome. It creates additional procedures and further work, at least for the Secretariat for Legislation, which may need to review the material in its entirety once again. When modifications are not substantial, the GSG could do these final adjustments directly - in co-operation with the Secretariat for Legislation, as needed - keeping control over the entire text within the GSG.

Communicating government session decisions is mostly transparent and well established. Most documents are made public. Only confidential material is not published, with very occasional exceptions (e.g. the July 2013 decision on the Plan for Internal Restructuring of Public Sector was initially kept confidential).

The network of PR and communications staff from within the line ministries is commendable and similar to good practice in EU Member States. In addition to discussing and co-ordinating acute government communication issues, the network has worked to improve the quality of policy work. 


\subsection{Legislative framework for policy development and interministerial co-operation}

The legislative process in Montenegro (proposal for a law, submission, adoption and publication) is prescribed by a number of different legal acts, from those with the highest legal power (The Constitution of Montenegro) to those governing the organisation and manner of government work ${ }^{27}$ and those prescribing analyses and decision making (e.g. Rules of Procedure of the Government [RoP] ${ }^{28}$, Legal and Technical Drafting Rules and Guidelines for harmonising Montenegrin legislation with the legal order of the European Union ${ }^{29}$, and Rules of Procedure of the Parliament). In addition, the law on publication of regulations and other documents ${ }^{30}$ details the way laws are to be published.

Most important for policy analysis is the Regulatory Impact Assessment (RIA), formally introduced into the Montenegrin regulatory system with the entering into force of the RoP as of 13 January 2012.

In 2012, the Government also introduced two decrees to regulate i) stakeholder participation (Decree on the Manner and Procedure of Co-operation of State Administration Authorities and Non-Governmental Organisations); and ii) public consultation (Decree on the Manner and Procedure of Implementation of Public Consultations in Preparation of Laws).

\section{Assessment}

The regulations clearly prescribe the issues that must be covered in the paperwork submitted to the government session to justify a policy proposal, including minimum information on public consultation and opinions of the Secretariat for Legislation and the key ministries. The regulation is implemented routinely and checked by the General Secretariat of the Government (GSG) before placing items for the consideration of the Government.

The new procedures for the involvement of non-governmental organisations (NGO) have increased interaction between state authorities and interested organisations. In reality, this co-operation depends on personal trust and time available for preparing the new policy documents. Nevertheless, the legal framework provides a good basic requirement for consultation although implementation is not always precise (e.g. article 2 of the decree on public consultation foresees public debate in the initial phase of preparation of a law; there are as many cases where public consultation is organised very late in the drafting process).

Consultation within government is also limited. According to the regulation for interministerial consultation, not all ministries need to be consulted with draft laws and strategies. The RoP foresee that only ministries affected by proposals must be consulted before submission to the Government. This pragmatic solution leaves room for judgement and gives opportunities for ministries to do the minimum in gathering the views of other parts of state administration.

Notable is the lack of specific requirements for the preparation and content of the sector strategies or work plans prepared by the ministries. For example, there is no obligation to include budgeting in these planning documents, with the exception of broad fiscal assessment statements included in the RIA form for sector strategies.

Equally, there is opportunity to specify timing requirements of RIA documents and their availability during public consultation (see section 2.2.2).

\footnotetext{
27 Regulation on the organisation and manner of operation of the public administration, Official Gazette of Montenegro, 5/12.

Official Gazette of Montenegro, 03/12.

29

Official Gazette of Montenegro, 2/10.

30

Official Gazette of Montenegro, 05/08.
} 


\section{2}

Policy development arrangements and capacity in the ministries

Similar to other European countries, the responsibility for policy development is primarily with the ministries. For good policy development (including law drafting), all ministries need to have staff who have acquired good knowledge of the challenges and opportunities in the policy areas of the ministry as well as good understanding of the acquis in their area, and who have a thorough understanding of policy making procedures. This needs to be supported with structures that enable proper information exchange and co-ordination within the ministry and with other stakeholders.

\subsubsection{Policy development structures}

Respective acts on internal organisation and systematisation outline the ministry structure and the responsibilities of management positions and departments. In Montenegro, the central regulation foresees certain staff positions (such as state secretaries, secretaries of ministries, director generals), but does not include standardised structural units for horizontal policy co-ordination functions (such as co-ordination of European Integration [EI] affairs). In most cases, annual work and resource planning is co-ordinated by the secretary of a ministry who has dedicated staff members to compile the necessary documents on the basis of input of sector departments.

In the ministries, general directors are responsible for policy development ${ }^{31}$ (or heads of departments, in some cases). Those responsible for a particular policy area are also typically responsible for the necessary preparations for transposition of the acquis in that area. This pattern is also followed in the structure for EU accession negotiations, where deputy ministers normally lead the working groups and the work within negotiation chapters.

In addition, the Law on State Administration ${ }^{32}$ stipulates that ministries may appoint one or more state secretaries to be in charge of policy development and monitoring its implementation. Up until recently, state secretaries were appointed only in the MFAEI. In early 2013, these positions had also been established within a number of line ministries ${ }^{33}$.

Specialised departments needed to serve as a nucleus for El co-ordination and policy planning exist in a number of ministries, but not all. Where they do exist, their focus is on planning Instrument for Pre-Accession Assistance (IPA) funds or co-ordinating El affairs (or both, as with the Ministry of Finance $[\mathrm{MoF}])$, but they do not normally cover the overall policy co-ordination of the ministries.

The placement of specialised analytical staff varies across the ministries. In the Ministry of Agriculture, for example, responsibility for RIA was assigned to two independent advisors trained in RIA and experienced in fiscal analysis. In the Ministry of Economy, no centralised unit performs the tasks of policy development, but each department analysed budget implications and RIA aspects, and usually co-ordinated within each working group ${ }^{34}$.

To ensure adequate analytical attention and co-ordination in preparing new regulation or strategies, there is a widespread practice of forming working groups. In some cases, these are composed only of ministry staff or the staff of several relevant ministries. However, the involvement of non-governmental experts has increased in the last two years.

31 Although the Government has formally changed the position of deputy ministers to general directors within ministries, a number of persons carrying out these functions are still called deputy ministers.

32 Article 41.

The decision of the Government of 31 January 2013 to appoint for the first time state secretaries to the Ministries of Interior, Finance, Justice, Sustainable Development and Tourism, Economy and Agriculture. State secretaries are not civil servants but political appointments as set out in Article 41a of the Law on State Administration. Their employment relations are, however, managed in accordance with the Law on Civil Servants.

34 Findings from research and interviews undertaken for SIGMA by Institut Alternativa. 


\section{Assessment}

The total public sector employment in Montenegro is comparable with many EU countries (relative to total working-age population); as such, the ministries in Montenegro tend to be small compared to their functions. The Ministry of Science has only around 25 employees and the Ministry of Culture has a little over 30. Considering these ministries include administrative and financial services and need to have professional knowledge in procurement and other specialised areas, there are limited resources for analysing the respective policy areas and engaging with the demanding stakeholders in their sectors on policy matters.

Resourcing is not much different in some bigger ministries, such as the Ministry of Economy and the Ministry of Agriculture and Rural Development. With a staff of around 100 and 60 respectively, they also have sizeable policy execution functions, such as managing grant schemes for small and medium-sized enterprises (SME) or having the Paying Agency for agriculture subsidies as part of the ministry.

The Plan for Internal Restructuring of the Public Sector ${ }^{35}$ provides an opportunity to improve policy capacities in ministries with a sizeable administration. There is less room to adjust the capacities (while meeting the staff reduction targets) in ministries with smaller sector administrations that are yet under significant pressure to recruit for the purposes of increasing capacity to implement new regulation coming from the acquis.

Ministries generally consider the resources needed to meet requirements and commitments during a year. However, most ministries lack analytical staff, and thorough knowledge of policies is held by a small number of experts. These constraints are often resolved by engaging external consultants to work on policy analyses and preparation. This practice, if used regularly, undermines the capacity building element of policy analysis and debate. Particularly in the process of EU accession negotiations, the Government risks losing the opportunity to acquire skills that will be of benefit after accession and, more immediately, the skills needed for analysing the actual implementation of these policies. A more sensible strategy would be to prioritise various policy initiatives over time, but this requires stronger focus on medium-term planning.

Ministries do not have dedicated legal departments and, as discussed in section 2.2.2, there is a lack of staff with professional skills in drafting laws. Another structural weakness arises from a lack of staff able to support economic analyses and fiscal impact estimations. Montenegro's ministries are not set up to respond effectively to potential demand from the co-ordinating bodies for specific economic policy matters, e.g. report on structural reforms in preparing the Pre-Accession Economic Programme. In this case, MoF requests are often met by budget and finance units without involving people who know the substance in the ministries ${ }^{36}$.

Policy development capacity of ministries remains a challenge due to staffing. The current practice places too much burden on middle management, which acts as sole subject experts, action co-ordinators and drafting experts. On the positive side, the general directors and heads of departments have clear responsibility for their policy areas within the Government and these are, in most cases, clearly recognised by peers in other ministries and agencies.

\subsubsection{Policy development processes}

Policy development processes as regards government decision making are discussed in section 1.3. The current section describes and analyses how the policy work is organised and to what extent the process is followed by the ministries.

35 Adopted by the Government in July 2013 with a deadline for ministries to propose their internal reorganisation and downsizing plans by the end of the second quarter in 2014.

36 Fiscal Impact Assessment of Structural Reforms, Montenegro case study, Centre of Excellence in Finance. 


\section{Planning of ministry work and resources}

Ministries plan their work and resources primarily through sector-specific strategies and annual work plans, which also provide input for the annual Government Work Programme and the annual budget preparations.

The annual work plans of the ministries include an overall statement of key challenges and objectives, a description of strategic priorities in the sector and a focus on activities by the sub-sectors under the ministry. Annual work plans do not need to include references to financial or human resources.

There are no particular rules or requirements established for the sector-specific strategies that the Government is to approve. There is also no agreement on which strategies are to be decided by the Government and which can remain at the level of individual line ministries as more operational planning documents. Currently, Montenegro has more than 60 sector strategies formally in force ${ }^{37}$.

Ministries are obliged to submit to the Government annual reports on their work. These should contain an overview of the implementation of the laws and other acts, as well as an overview of the realisation of the Government's programs and its conclusions ${ }^{38}$. There is an additional obligation for ministries to submit separate reports upon special request by the Government.

\section{Assessment}

The total number of sector strategies that are in force in Montenegro is relatively high, but the concern is that they are implemented in various degrees. The chapter tables within the Programme of Accession of Montenegro, as adopted in the end of 2013, reveal plans for many more new strategies that add to the mix of formal strategies, each potentially with their independent structure, varying level of detail and random relation to budget and human resource planning. This situation can lead to unrealistic expectations by various stakeholders and overly optimistic plans within the Programme of Accession of Montenegro. In some cases, if implementation cannot be ensured, this could eventually undermine the credibility of negotiation commitments.

Since there are virtually no detailed requirements for the content or the role of sector-specific strategies, they all cover different time periods and include different information. Table 5 analyses the information and reporting aspects for some existing sector strategies. In fact, the picture is even more mixed, since many strategies are prepared with substantial help from external consultants.

The vast majority of current sector strategies do not have any information on either estimated financing needs or sources of funding. Where financing needs are presented, they are not in line with the country's actual resource plans (e.g. the annual budget or the IPA programmes). Moreover, the sector strategies are not updated often enough to be considered genuine planning and co-ordination tools. This is already becoming a weakness, since IPA planning is moving to a more multi-annual basis and the national sector policies cannot prepare sufficiently robust policy plans to enable the Ministry of Foreign Affairs and European Integration (MFAEI) to plan resources relying on them.

There are impacts on the ability of ministries to contribute to the more horizontal economic policy programmes ${ }^{39}$. Structural reforms are often part of the existing sector strategies, but the ministries do not currently have proper capacities to aggregate and communicate their structural reform input to the MoF. Unless the strategic planning framework is streamlined and strengthened, Montenegro may face difficulties in the future in participating in the EU's economic governance framework and in planning for Cohesion Policy financing.

\footnotetext{
37 Depending on a definition of sector strategy, this number is in some counts even higher than 100.

38 Article 62 of the Law on State Administration.

39 Development Directions of Montenegro and Pre-Accession Economic Programme.
} 
Table 5. Information and reporting strategies in sample sectors

\begin{tabular}{|c|c|c|c|c|c|c|c|c|c|c|c|}
\hline \multirow[t]{2}{*}{ Strategies and action plans in place } & \multicolumn{5}{|c|}{$\begin{array}{c}\text { Frequency of } \\
\text { reporting }\end{array}$} & \multicolumn{3}{|c|}{$\begin{array}{c}\text { Type of indicator } \\
\text { used }\end{array}$} & \multicolumn{3}{|c|}{$\begin{array}{c}\text { Sources of } \\
\text { data }\end{array}$} \\
\hline & 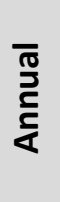 & 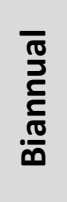 & 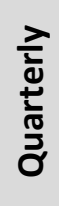 & 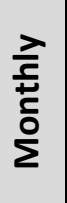 & 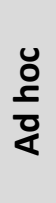 & $\frac{c}{\frac{0}{20}}$ & $\begin{array}{l}\text { 苛 } \\
\text { 节 }\end{array}$ & 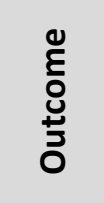 & 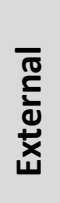 & 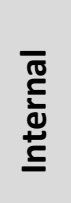 & 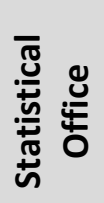 \\
\hline $\begin{array}{l}\text { Energy Policy Document } \\
\text { Energy Development Strategy } \\
\text { Action Plan 2008-2012 }\end{array}$ & $\checkmark$ & & $\checkmark$ & & $\checkmark$ & & & $\begin{array}{c}75- \\
100 \%\end{array}$ & $\checkmark$ & & $\checkmark$ \\
\hline $\begin{array}{l}\text { Strategy for Development of SMEs } \\
2011-2015 \\
\text { Strategy for Competitiveness at } \\
\text { micro level } 2011-2015\end{array}$ & $\checkmark$ & & & $\checkmark$ & $\checkmark$ & $\begin{array}{c}50- \\
75 \%\end{array}$ & $\begin{array}{c}0-25 \\
\%\end{array}$ & $\begin{array}{c}0-25 \\
\%\end{array}$ & $\checkmark$ & & $\checkmark$ \\
\hline $\begin{array}{l}\text { Strategy for the reform of the } \\
\text { Judiciary 2007-2012 } \\
\text { Action Plan }\end{array}$ & $\checkmark$ & $\checkmark$ & $\checkmark$ & $\checkmark$ & & $\begin{array}{l}50- \\
75 \%\end{array}$ & $\begin{array}{l}25- \\
50 \%\end{array}$ & & $\checkmark$ & $\checkmark$ & $\checkmark$ \\
\hline $\begin{array}{l}\text { Strategy of Pubic Administration } \\
\text { Reform 2011-2016 } \\
\text { Action Plan }\end{array}$ & $\checkmark$ & & & & $\checkmark$ & $\begin{array}{c}75- \\
100 \\
\%\end{array}$ & & & $\checkmark$ & $\checkmark$ & \\
\hline $\begin{array}{l}\text { National Strategy for Employment } \\
\text { and Human Resource Development } \\
2012-2015\end{array}$ & $\checkmark$ & & $\checkmark$ & $\checkmark$ & $\checkmark$ & $\begin{array}{l}50- \\
75 \%\end{array}$ & $\begin{array}{c}0-25 \\
\%\end{array}$ & $\begin{array}{c}0-25 \\
\%\end{array}$ & $\checkmark$ & & $\checkmark$ \\
\hline $\begin{array}{l}\text { Transport Development Strategy } \\
2008-2018 \\
\text { Action Plans }\end{array}$ & $\checkmark$ & & $\checkmark$ & & $\checkmark$ & $\begin{array}{l}50- \\
75 \%\end{array}$ & $\begin{array}{l}25- \\
50 \%\end{array}$ & $\begin{array}{c}0-25 \\
\%\end{array}$ & $\checkmark$ & & $\checkmark$ \\
\hline
\end{tabular}

Source: Information from questionnaires of five ministries for the World Bank project "Monitoring and Evaluation Capacity Development for the Western Balkans and Turkey", Inception Report.

The overview indicates that the information and reporting for each sector strategy differs. In practice, monitoring of progress is carried out routinely, but regular stock-taking often does not go beyond analysis on actions completed. Only in exceptional cases are monitoring and reporting actions that are planned and announced not really carried out ${ }^{40}$.

The annual work plans of the ministries are in line with the annual Government Work Programme. The main weakness is that, since work plans are strongly geared to legislative work and reporting to the Government, they contain no written consideration of the planned budgetary resources (including staff).

Annual work plans often have a strategic 'umbrella', but proposed activities are, in some cases, simply a composite of the different sectors (e.g. the Ministry of Agriculture and Rural Development 2013 annual work plan, wherein sector plans were not harmonised even in terms of style and presentation). This confirms interview feedback that the ministries do not have permanent staff members dedicated to co-ordinating work and resource planning at the level of the ministry as a whole.

40 This has been the case with the Public Administration Reform Strategy during the first years of its implementation. 


\section{Policy analysis and estimation of impacts of new policies}

For the Government to make informed decisions, policy analysis should include consideration of different options and their consequences. The extent and complexity of the analysis should be proportionate to the importance of the issue.

The new procedures for RIA were put in place in January 2012. All ministries are required to analyse whether regulatory intervention is needed and, if so, which option offers the best solution. This is submitted along with the proposed law ${ }^{41}$. There are four areas that do not require the submission of a RIA: the budget bill, legislation dealing with the aftermath of emergencies, national security legislation, and legislation which transposes EU legislation where no options on how to implement the legislation are available. Additionally, the drafter may decide not to develop a RIA, as long as he or she is able to explain and substantiate the reasons.

Fiscal impact assessment is required as part of the RIA procedure ${ }^{42}$, and the template for a RIA report includes a set of ten questions answered by the initiator of the draft regulation.

The MoF handles the quality control of the RIA procedure, scrutinising both the overall completeness and quality of the RIA documents and the correctness of the fiscal impact estimation. The RIA reports and the MoF opinion are both delivered to the Government along with the policy proposal. The procedure is the same if the drafter provides rationale that the RIA report is unnecessary. The MoF issues opinion on such a decision as well.

\section{Assessment}

The rate of implementation of the new RIA procedure has been remarkably high during the first 18 months of implementation. Figure 3 demonstrates the distribution of RIAs across the public administration in 2012 and shows that, in most cases, the MoF has approved these without pointing to significant problems ${ }^{43}$.

41 The Rules of Procedure of the Government, Article 33 mandates an assessment of impacts of a draft law or by-law.

42 Article 2 of the RIA Manual.

43 In 13 cases, they negotiated with the proposing ministry to ensure that the analysis was agreed upon. The MoF changed opinion due to the fact that the proposer adopted the amendments of the MoF or that the MoF eventually agreed with the proposer's rationale once it had been more fully explained. 
Figure 3. Regulatory Impact Assessments prepared by ministries in 2012

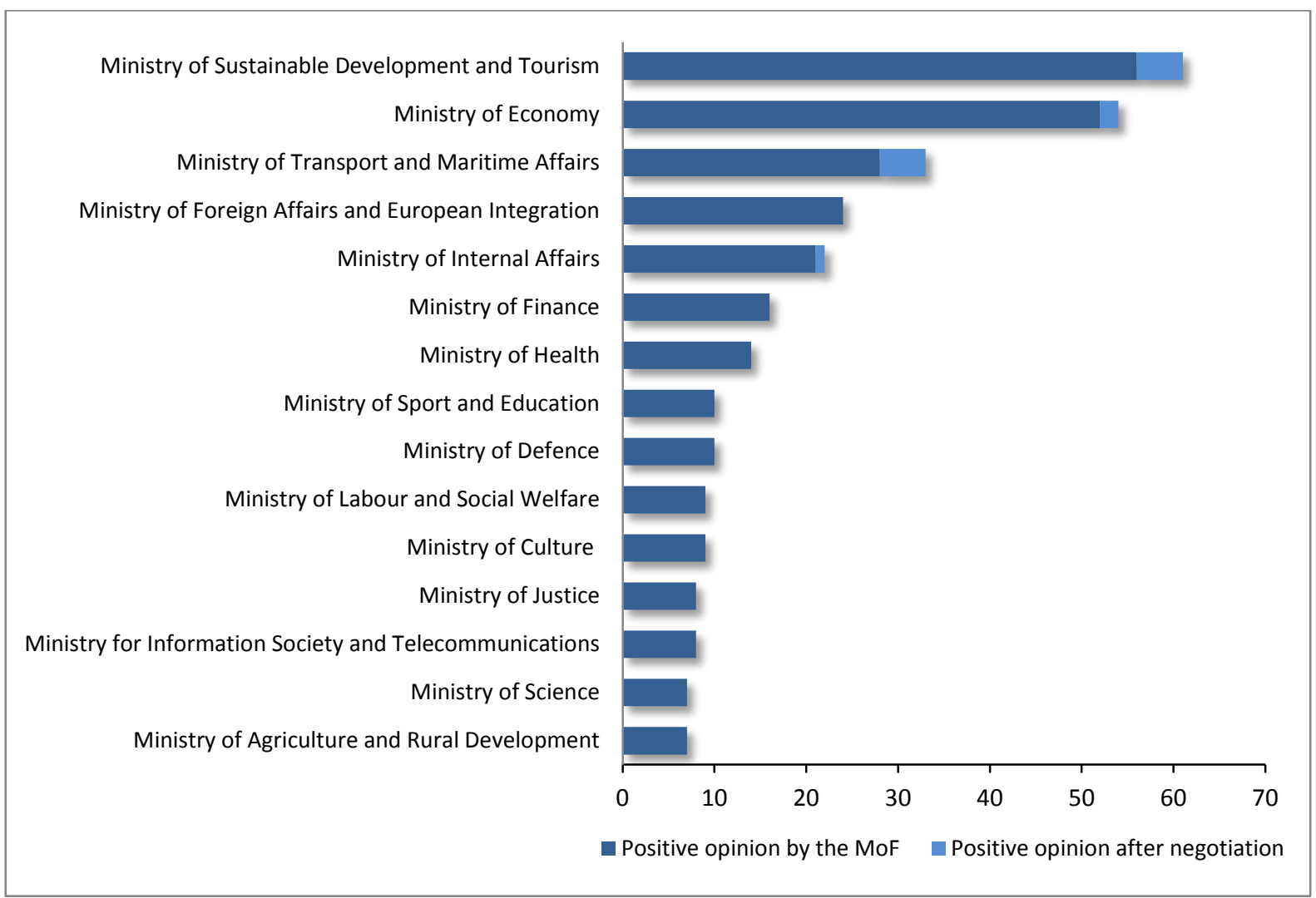

Source: Ministry of Finance.

The content in RIA documents is still often weak. Analysis in some areas of the process, such as public consultation, tends to be fairly superficial and does not demonstrate how the consultation process actually influences the development of a policy ${ }^{44}$. As described, the quality of fiscal analyses varies widely and is not always complete with respect to questions foreseen in the RIA template.

Although the routine procedure and practice of preparing RIAs is commendable, in practice, they are too often prepared in the late stages of law drafting and are not used to support public consultations. Furthermore, the current system does not encourage proper discussion of policy alternatives prior to discussion of a full draft law.

Nearly two years after introducing the new system, the implementation of the RIA process has been reviewed and six areas have been identified for improvement:

44 Analysis of six sample RIAs from the Ministry of Economy, Ministry of Health and MoF found varying quality in the detail provided. 
Table 6. Summary of assessed improvements to Regulatory Impact Assessment implementation

\begin{tabular}{|c|c|}
\hline Systemic challenges for the implementation of RIA & Impact \\
\hline $\begin{array}{l}\text { Regulatory Impact Assessments are required only at } \\
\text { a late stage of draft policy proposals, prior to the } \\
\text { submission of the material for government } \\
\text { consideration. }\end{array}$ & $\begin{array}{l}\text { - Proper analysis of the estimated impacts } \\
\text { cannot be used during public consultations } \\
\text { that often occur earlier. } \\
\text { - Potential alternatives are not discovered } \\
\text { early enough in the process for them to be } \\
\text { considered instead of the drafted text. }\end{array}$ \\
\hline $\begin{array}{l}\text { The quality of analysis in areas such as fiscal } \\
\text { assessment varies greatly and the focus on } \\
\text { implementation tends to be limited. }\end{array}$ & $\begin{array}{l}\text { - There is no real appreciation of cost of the } \\
\text { proposed measures - no post facto review } \\
\text { carried out - so the total cost of the } \\
\text { initiative is unknown. } \\
\text { - Proposal is likely to fail if implementation } \\
\text { and monitoring are not accounted for when } \\
\text { designing the strategy or law. }\end{array}$ \\
\hline $\begin{array}{l}\text { The level of detail provided is often superficial and } \\
\text { does not, for example, demonstrate how the } \\
\text { consultation process actually influenced the } \\
\text { development of a policy. }\end{array}$ & $\begin{array}{l}\text { - Consultees will be less engaged if they do } \\
\text { not see how their views have fed into the } \\
\text { finalisation of the Government's decision. }\end{array}$ \\
\hline $\begin{array}{l}\text { There are four areas that do not require the } \\
\text { submission of a RIA and drafters are able to decide } \\
\text { not to develop a RIA as long as they are able to } \\
\text { explain and substantiate the rationale. }\end{array}$ & $\begin{array}{l}\text { - These exceptions pose a risk to the success } \\
\text { of the RIA system: loopholes can be } \\
\text { exploited by ministries. } \\
\text { - The number of exceptions to the RIA } \\
\text { process is likely to increase as the rate of } \\
\text { EU transposition increases. }\end{array}$ \\
\hline $\begin{array}{l}\text { The analytical capacity to undertake policy analysis } \\
\text { within ministries is varied. }\end{array}$ & $\begin{array}{l}\text { - Poor practices could be replicated within } \\
\text { ministries without remedial action. }\end{array}$ \\
\hline $\begin{array}{l}\text { RIA oversight focuses on completion of paperwork, } \\
\text { with quality assurance taking lower priority due to } \\
\text { resource pressures and the wide remit of the unit } \\
\text { within the MoF. }\end{array}$ & $\begin{array}{l}\text { - Quality and consistency of RIAs varies } \\
\text { significantly. } \\
\text { - Ministries are unable to get targeted advice } \\
\text { and guidance while drafting their } \\
\text { proposals. }\end{array}$ \\
\hline
\end{tabular}

Source: SIGMA.

\section{Capacities for drafting law}

The Government of Montenegro has detailed legal and technical rules for drafting laws and by-laws. These are monitored by the Secretariat for Legislation, the central government body for ensuring that the Government produces regulation in an orderly manner.

The overall volume of legislative activities varies and may change considerably year to year. Figure 4 shows the legislative and strategic workload with respect to laws by five ministries over two years. Draft tables for the Programme of Accession of Montenegro also show a very demanding regulatory workload for state institutions in the coming years. 
Figure 4. Output of laws and strategic documents by selected ministries

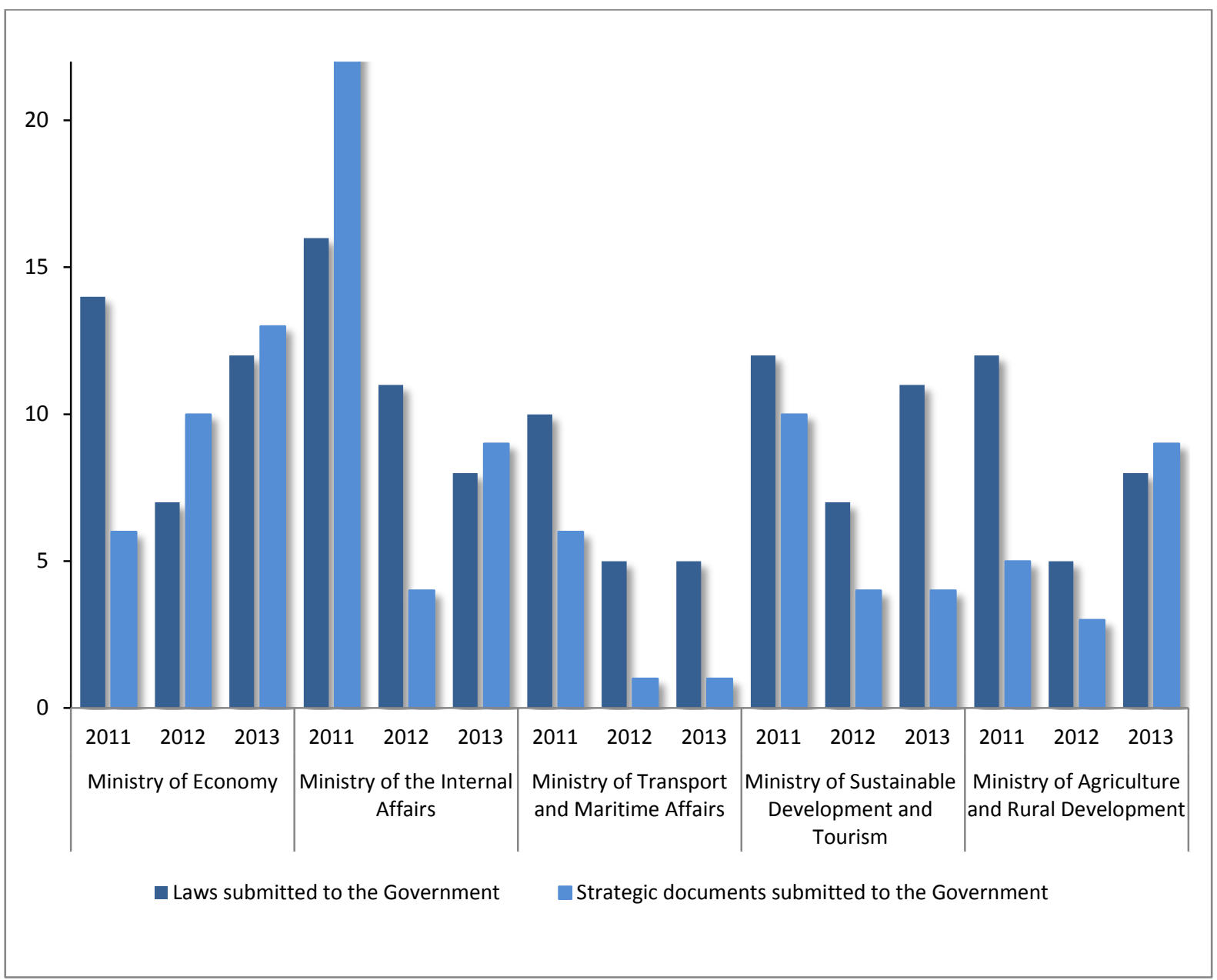

Sources: reports on realisation of annual Government Work Programmes for 2011 and 2012, and reports on the work of ministries.

All legal acts of Montenegro are available through the Legal Information System, which is an upgrade of the electronic edition of the Official Gazette of Montenegro (established beginning of 2010).

\section{Assessment}

A number of cases reveal deficiencies in the quality of draft regulation. The Secretariat for Legislation in particular has intervened to ensure that laws and by-laws are decided within Montenegro's constitutional and legal systems. The need for such oversight and intervention is more frequent when translation of directives is necessary or foreign experts prepare national regulation.

Despite several years of implementation of legal and technical rules for law drafting, the Secretariat for Legislation overseeing their implementation still finds frequent problems in the accuracy and coherence of draft legal texts. One cause is a lack staff with professional law drafting skills. Considering the size of many ministries, this is perhaps understandable; but, the Government will need to consider other means to assist law making from the beginning of the drafting process (e.g. by adjusting the mandate, current responsibilities and/or staff resources of the Secretary for Legislation).

Another challenge to the overall quality of regulation is that, despite provisions in the legal and technical rules for law drafting, secondary legislation is mostly prepared after the relevant law has been passed. In some cases (one partial instance being the Law on Civil Servants and State Employees ${ }^{45}$ ), secondary legislation is finalised when the law itself is already in force. In such situations, it is difficult to ensure that the law contains the correct and precise delegation norms for secondary legislation, negatively impacting 
implement of the regulation. In addition, with the information on secondary legislation missing, the analysis underpinning RIA (including evaluation of fiscal impacts) cannot always be precise at the time the draft law is discussed and decided upon.

The variation in overall volume of legislative activities seen in Figure 4 is even higher in individual ministries and requires giving specific attention to their annual resource planning process. Strengthening legal drafting support from the centre (e.g. by the Secretariat for Legislation) may be more feasible than expecting all ministries to fulfil these demanding competencies when legislative drafting is more intensive.

There are no formal requirements or mechanism for planning implementation. The material submitted to the Government does not need to contain an implementation plan. Implementation plans and action plans are nevertheless sometimes adopted on a case-by-case basis for certain agreements or laws, such as the Criminal Code, The Law on Free Legal Aid, The Law on Misdemeanours, The Law on Notaries, but only upon their adoption by Parliament.

While the RoP set the procedural framework and the main requirements for new legislative proposals, including detailed requirements for policy preparation, they lack the specific follow-up obligations needed for the ministries to analyse the implementation of policies. As EU attention moves towards the extent of implementation of acquis-related legislation in Montenegro, it is advisable to prepare the system that analyses and detects implementation difficulties. This can be developed into a system of ex post evaluation of priority legislation or policies. To make the task feasible, the focus should only be on key legislation. This would have multiple benefits, including feeding the negotiation structures with credible information about the actual level of implementation. If planned well, these analyses can even be co-financed by the Instrument of Pre-Accession Assistance (IPA).

\section{Co-ordination between ministries and with the socio-economic interest-groups}

The rules for interministerial and public consultation are established through the RoP and the two government decrees on the involvement of non-governmental interest groups discussed in section $2.1^{46}$. Larger, more active NGOs, such as national business associations and trade unions, have four regular opportunities to influence the draft policy proposals: i) participation in the working groups dedicated to the development of the particular policy (e.g. a law); ii) public consultations; iii) advisory bodies of the Government (e.g. the Regulatory Council); and iv) public hearings in Parliament.

The Council for Co-operation with NGOs, which operates as part of the $\mathrm{GSG}^{47}$, is a government body responsible for guiding and increasing the capacity of ministries to involve civil society organisations into policy development.

Formal consultations within government structures do not require receiving opinions from all ministries. It is obligatory to obtain the opinion of the MFAEI, Ministry of Interior, MoF, Ministry of Justice, the Secretariat for Legislation and any ministry that is directly affected by the draft proposal ${ }^{48}$. The final content of a law and other proposals that previously fail to comply with the opinions of the competent institutions must be agreed upon by the relevant Deputy Prime Minister. There is no regular forum for the highest level civil servants, such as secretaries of ministries or state secretaries, to co-ordinate work or discuss differences in opinion on policy.

\section{Assessment}

There is a strong emphasis on, and legislative basis for, the need to communicate proposed legislative changes with those affected by the proposals. There is a systemised approach to engagement with NGOs,

46 The Decree on the Manner and Procedure of Co-operation with Public Administration Bodies and NGOs (Official Gazette of Montenegro, 7/12); the Decree on the Manner and Procedure of Conducting Public Consultation in the Preparation of Laws (Official Gazette of Montenegro, 2/12).

The main goals of this council are: i) further the development of institutional mechanisms of co-operation and participation of NGOs; ii) monitor strategy implementation; and iii) improve relations between the Government and NGOs.

48 For more details, see Article 40 of the Rules of Procedure of the Government. 
underpinned by a government decree ${ }^{49}$. The working group system used to support the policy and legislative development process operates routinely. Stakeholders from outside the government structures feel that there are adequate opportunities to engage with the Government and influence policy development ${ }^{50}$. These range from informal engagement to participation in working groups, public hearings and representation on the consultative bodies of the Government, such as the Regulatory Council. During the past two years, the involvement of non-governmental experts has increased, particularly in the preparation of strategies and related action plans. At the same time, there are cases where interested and competent NGOs are not included in the work, without any apparent reason.

The working routines foreseen by the RoP for co-ordination among ministries are implemented normally, with few exceptions. Often, co-ordination among ministries is handled on a fairly informal basis.

Most interviews indicate that the MoF, Secretariat for Legislation and other bodies determined by the RoP are regularly consulted. However, ministry opinions are regularly merely technical approvals: simply to fulfil the obligation to respond, rather than provide comment on the content. This is a common drawback of a cross-governmental clearance process.

A notable case of non-application of the normal consulting arrangements was identified in the EU accession negotiation framework, when chapter 25 (Science and Research) was provisionally closed the Government had committed to increase national investment in research and development. This commitment was taken without proper consultation with the MoF. As in previous rounds of EU accession negotiations, there is a risk that ministries may misuse the El flag in two ways by: i) avoiding regular procedures for co-ordination and decision making (e.g. chapter 25); and ii) regulating for unnecessary procedures or negotiating for more resources than the acquis actually requires.

\section{European integration affairs in the ministries}

The Government has established norms and regulations which specify the El-related obligations and tasks of the line ministries. In 2010, the Government introduced obligations for line ministries to prepare the Table of Concordance for all draft laws in order to provide a detailed comparison of the specific articles of the national legal act with corresponding articles of EU measures one by one.

With a gap in previous years in the central planning framework for El affairs, it is impossible to accurately evaluate the amount of El-related work the ministries have pursued in the past few years. However, the Directorate for Harmonisation of Legislation within the Directorate General for European Affairs (DGEA) checked 167 legal acts (laws and by-laws) adopted by the Government in 2012, of which 45 were deemed to be 'harmonised' with relevant EU legislation.

The MFAEI has prepared procedures for all negotiating working groups whose main tasks have been described: i) participate in examining Montenegrin legislation and evaluating its conformity with the acquis; ii) draft negotiating positions with the support of the other governmental agencies and institutions; and iii) report on progress of implementing commitments.

All of the working groups have been established. Members and sub-group members are appointed on the proposal of the Chief Negotiator. In practice, members are proposed by the lead ministry in consultation with the heads of state authorities and other bodies, institutions and organisations. The working groups are normally chaired by general directors of relevant ministries. Members are mostly government officials and, but most also include representatives from civil society and interest groups. In some cases, the group chair is not a public official.

\section{Assessment}

As in all other areas, there is limited, if any, specialised El-related capacities within the ministries. Most officials tend to fulfil EU accession-related functions on top of their other duties. However, this should not

49 Decree on the Manner and Procedure of Co-operation between State Administration Authorities and Non-Governmental Organisations.

50 Four NGOs were interviewed. One suggested that they would like greater dialogue with the Government before a law is drafted. 
be viewed as a shortcoming. Ultimately, integration requires that all 'domestic' policy making be increasingly achieved through the lens of accession goals. Current conditions tend toward avoiding the artificial separation of accession-related tasks from 'normal' tasks, which can occur by employing separate staff to perform them. Additionally, countries with a very small public sector and scarce resources could not and should not build up parallel administrative capacity exclusively dedicated to El. For such countries, it is all the more important that ministries avoid duplicating procedures or setting up parallel structures.

Nevertheless, there remains a need to promote, monitor and ensure the coherence of El-related tasks within ministries. At the moment, this is not always the case. A number of ministries have or are planning to establish El co-ordination units, or have tasked existing units with this function or have named a responsible officer as a contact for EU accession co-ordination. All of these models are workable and, importantly, allow ministries sufficient and advisable flexibility to decide best mechanisms with respect to their level of obligation, which differ.

That being said, practically speaking, such mechanisms are normally established prior to the start of the EU accession negotiation process. Thus, their work has been orientated towards co-ordinating their ministry work within the Stabilisation and Association Agreement (SAA) process. Newly established working groups within the accession process have limited links with those arrangements. There is an emerging possibility that ministries will develop internal co-ordination mechanisms and practices for working groups separate from established co-ordination structures and habits. In some cases, the nominal co-ordinator of a ministry's El-related functions, has been tasked with monitoring and reporting developments, which before included only the SAA related work of the ministry. He or she also serves as the main contact point for the DGEA and represents the respective ministry in the Commission for European Integration. It is not uncommon that this ministry representative actually has i) no involvement in the newly formed working groups the ministry leads (is neither the chair nor a participant, thus having no inclusion in the tasks they work on), and ii) holds no regular co-ordination meetings with the responsible officials (general directors). Moreover, as the latter tend to outrank the nominal co-ordinator, there is no easy way for him or her to attain this information.

If the ministry only has one working group to lead, this set-up may not pose a major problem. Where the ministry has several working groups and/or sub-groups, internal co-ordination via this mechanism will become an issue. This is especially true as new responsibilities emerge in parallel with existing co-ordination structures. Therefore, it is strongly advised to ensure established co-ordination mechanisms be included in - or, ideally, submerged into - the new workflow of the negotiation working groups. Ideally, merging the association and accession processes should be mirrored at the interministerial level (see section 1.3.2).

In terms of ensuring co-ordinated policy development and execution, most working group chairs are general director level. This is commendable; in order to fulfil their tasks effectively, to mediate and solve conflicts and to make binding commitments on behalf of the ministry (and the Government) on deliverables (both on content and deadlines), chairs must be able to task officials in their own and other ministries and bodies in an enforceable manner. They should not only have ministerial authority and enjoy the trust of the minister, but be seen as legitimate and impartial in this role by other government institutions and bodies, as well as by Parliament.

This role and status may prove problematic for appointees who are not government officials. For example, a Chamber of Commerce representative was nominated chair of the working group on the right to establishment and freedom to provide services. The negotiation process involved in the implementation of the acquis in internal market of services unavoidably involves decisions which may give preference to some market participants over others. Also, and despite similar cases in other accession countries, a representative of the Montenegrin Central Bank (which, according to the acquis, must be fully autonomous and indeed separated from the Government) also chaired negotiations on behalf of the Government in the field of economic and monetary union.

In order for the general public to maintain trust in the El process, arbitration for these decisions has to be as objective as possible and the persons making decisions need to be accountable to democratic 
institutions. Thus, the question of a link between the chair and the minister responsible, and ability of the chair to fulfil his or her roles, should be tackled with outmost care.

Finally, ministry planning of EU accession-related activities has thus far also been ad hoc and the costs of commitments not normally included in the plans. The annual Government Work Programme for 2013 contained actions related to El. This should change as the new Programme of Accession of Montenegro becomes a rolling planning document and the plans of the MFAEI include increased attention to costing. However, the ministries themselves need to prioritise the workload and budget for the process when drafting and developing negotiation positions. Crucially, in general, adopting negotiation positions and commitments in the Government must be conducted and channelled through the normal consultative mechanisms. Each draft negotiation position must be made available for scrutiny by the MoF before decisions are made by the Government. Thus far, this has not always been the case.

\section{Public communication and engagement}

In addition to regular public information-sharing, the GSG and its Public Relations Bureau are engaged in a number of other initiatives to involve the general public in government objectives. Table 7 illustrates the most visible recent government initiatives in public outreach. 
Table 7. Recent government initiatives to promote citizen participation

\begin{tabular}{|c|c|}
\hline Initiative & Detail and purpose \\
\hline E-petitions - Citizens' Voice & $\begin{array}{l}\text { - Launched } 9 \text { October } 2012 \text {. } \\
\text { - Every adult citizen of Montenegro or foreigner with } \\
\text { permanent residence may submit an e-petition in any field } \\
\text { within the Government's remit on the website. } \\
\text { - If supported by at least } 6000 \text { signatures ( } 1 \% \text { of the } \\
\text { population), the relevant ministry has to create a formal } \\
\text { motion, which will be considered by the Government, and, } \\
\text { if successful, submitted to Parliament. } \\
\text { Purpose: increase participation in government decision } \\
\text { making. }\end{array}$ \\
\hline $\begin{array}{l}\text { Misuse of government vehicles } \\
\text { on-line reporting service }\end{array}$ & $\begin{array}{l}\text { - Online service enabling citizens to report cases of misuse } \\
\text { of government vehicles. } \\
\text { - A mobile phone application has been developed which will } \\
\text { make reporting easier for the user. } \\
\text { - Citizens send photos of government vehicles which they } \\
\text { suspect have been misused (violating traffic regulations, } \\
\text { used for private purposes or after working hours, etc.). } \\
\text { - The Government publishes all photos immediately on an } \\
\text { official website http://www.gov.me/sluzbena vozila/ and } \\
\text { sends the reports to the public administration bodies using } \\
\text { those vehicles. } \\
\text { - Authorities send their responses and these are also } \\
\text { published. } \\
\text { Purpose: engage citizens to help the authorities tackle this } \\
\text { issue of misuse of public assets. }\end{array}$ \\
\hline $\begin{array}{l}\text { Campaign against the grey } \\
\text { economy }\end{array}$ & $\begin{array}{l}\text { - Initiative to encourage citizens to report cases of grey } \\
\text { economy (illegal employment, illegal construction, } \\
\text { value-added tax and excise duty evasion, etc.). } \\
\text { Purpose: identify and eradicate grey economy practices and } \\
\text { invest (part of) the penalty money to build that structure in the } \\
\text { society (a school, hospital, day care, etc.). } \\
\text { Note: historically, citizens are unwilling to report grey economy } \\
\text { because denunciation is traditionally perceived as } \\
\text { dishonourable. }\end{array}$ \\
\hline
\end{tabular}

Source: information from the Government of Montenegro Public Relations Bureau.

\section{Assessment}

Montenegro's initiatives to increase public participation in the operation of government are commendable. Several communication practices show a commitment to greater transparency and openness. Nevertheless, there are still many occasions when NGOs rely on formal information requests, which signals some weaknesses in providing information to the public.

The main weakness in government communications is that it often follows policy development, rather than supports it from the early stages. There is scope to align annual communications planning and PR in general to the work plans of the ministries. 
This part examines the role of the Parliament of Montenegro in public policy making, analysing the legal and institutional framework within which this role occurs. It also examines Parliament's performance in the exercise of central policy functions, including: legislation, budgeting, executive oversight and control, and, as a cross-cutting function, Parliament's responsibilities in the process of EU accession negotiations and the harmonisation of Montenegro's law with EU law.

It is worth highlighting at the outset some of the basic assumptions on which the following analysis and suggestions are based. First, Parliament has a positive contribution to make throughout all stages of the policy cycle, including: agenda setting, policy formulation, decision making, implementation and evaluation. However, its relative emphases in these areas vary. Policy formulation, notably in the form of bills, is typically dominated by the Government and formal authoritative decision making, through the adoption of legislation, is a key parliamentary function; however, Parliament's role is not restricted to the latter. Increasingly in European parliamentary democracies, legislatures have developed capacities for monitoring the implementation of legislation and for policy evaluation.

Second, the orientation towards enhancing the quality of policy affects not only the legislative process, but other key functions as well, including: the budgetary process, parliamentary oversight and control and parliamentary involvement in European integration (EI). In all four domains of parliamentary action, parliaments have a role to play, not just in ex ante scrutiny and holding the executive to account for its actions, but also in ongoing supervision as a means of improving the performance of public institutions.

Third, although the focus of this analysis is on the internal conditions shaping the impact of the Parliament of Montenegro on policy making, this contribution is decisively influenced by the quality of inter-institutional relationships, most notably concerning the Government, but also, amongst others, the public sector institutions such as the State Audit Institution, civil society and international bodies.

\subsection{Legal framework}

The normative framework that regulates the policy-related powers of the Montenegrin Parliament is comprehensive, including, among other things, the Constitution ${ }^{51}$, with its extensive and regularly amended Rules of Procedure of the Parliament. These contain the specialised laws that touch on the individual aspects relevant to the policy making powers and capacity of Parliament, such as: i) the Law on the Financing of Political Parties, which also envisages funds for regular work of parliamentary parties within Parliament; ii) the Law on Parliamentary Oversight in the Area of Security and Defence; iii) many legal acts that contain reporting requirements of public authorities and independent regulatory bodies to Parliament; and iv) the Rulebook on the Organisation and Systematisation of the Parliamentary Service.

\section{Assessment}

There is a differentiated legal framework in place with a clear hierarchy of norms. It is noteworthy that, notwithstanding the overriding importance of El, there is so far no single authoritative legal source that would set out the respective powers and responsibilities of the Government and Parliament in this field and, in particular, clearly establish the practices governing executive-legislative relations in El. The Rules of Procedure of the Parliament regulate the powers of the lead committees as regards legal harmonisation and compliance with the acquis, but they do not establish anything approaching a comprehensive framework for the effective parliamentarisation of the EU accession process. This is in contrast to some EU Member States, such as Germany, with its Law on Co-operation between the Federal Government and the German Bundestag in matters concerning the European Union (EUZBBG) and the Responsibility for Integration Law, or in Denmark, where Parliament has agreed with the Government to a series of legally binding reports on how to handle EU-related matters.

51

Notably its Part 3.1. 
The key components of the institutional framework encompass: the political leadership structure, political party groups, committees and the plenary, and the Parliamentary Service headed by the Secretary General.

\subsubsection{Political leadership structure}

The political leadership structure consists of the President and three Vice-Presidents of Parliament and the Collegium of the President, which includes the chairs of the parliamentary groups. The Secretary General participates in the work of the Collegium, while chairs of the committees take part in its deliberations, if needed. The Collegium, which during sessions sometimes meets up to three times a week, can be described as the central locus for managing the flow of timetables.

\section{Assessment}

Although relations within the Collegium are generally described as co-operative and advance timetabling appears to work well under normal circumstances, one issue deserves highlighting. No representative of the Government takes part in the meetings of the Collegium. Given the extent to which parliamentary business is driven by bills submitted from the Government, it is surprising that there is no representative from the Government charged with managing relationships with the legislature present. This is all the more so as ministers are not allowed to serve as deputies, so that there is already a strict institutional separation. It could be argued that the Government Work Programme is sufficiently reliable in allowing Parliament to establish its own plan of legislative work without the need of additional advance information provided by the Government. However, it merits emphasising that in 2011, out of 147 adopted laws proposed by the Government, 26 had not been included in the annual Government Work Programme for that year. In 2012, the percentage of successful bills not included in the Work Programme was even higher: 21 out of 73 adopted laws had not been contained in the annual Government Work Programme.

\subsubsection{Parliamentary party groups}

There are currently seven parliamentary party groups ("clubs") in Parliament. They include: the Democratic Party of Socialists; the Democratic Front; the Socialist People's Party of Montenegro; the Social Democratic Party of Montenegro; Positive Montenegro; the Bosniac Party; and the Members of Parliament club of Albanian parties (FORCA, Democratic Party), Croatian Civic Initiative and Liberal Party of Montenegro.

\section{Assessment}

As in other parliamentary democracies, the distinction between majority and opposition groups pervades their behaviour, notably as regards legislation and executive oversight and control. Their policy making capacity is limited for practical reasons. Members of Parliament (MP) do not have their own offices at the seat of Parliament; the accommodation of the groups is essentially limited to small meetings rooms, and groups have only between two and four support staff. Under the Rules of Procedure of the Parliament, each group is allowed to hire one secretary, paid out of parliamentary funds, and one or several professional consultants, depending on the size of the group.

The effectiveness of the groups has also been hampered by a high number of resignations of deputies during the course of the 24th convocation, 2009 2012. These resignations hit both of the governing parties, as elected deputies must leave Parliament upon entering the Government, but they also affected, albeit to a lesser extent, the opposition parties. During the 24th convocation, the initial composition of Parliament was changed 35 times. Under these conditions, agenda setting and policy formulation were largely beyond the capacity of the groups.

\subsubsection{Plenary and committees}

The main political working bodies in Parliament are the plenary and the 14 standing committees; there is also the Commission for the Monitoring and Control of the Privatisation Process. The committee structure 
is not fixed and can be altered through a change in the Rules of Procedures of the Parliament at any time during the convocation. During the 24th convocation, the number of committees grew from 11 to 14 . Committee membership varies in size between 11 and 13 deputies and committees are served by two to seven staff of the Parliamentary Service. The highest number is dedicated to the Economy, Finance and Budget Committee. Although the Rules of Procedure of the Parliament explicitly allow for the creation of sub-committees, so far, this possibility has not been used.

The level of parliamentary activity at plenary and committee level has been high, and there has been a clear trend towards an increased workload from the $23 \mathrm{rd}$ to the 24th convocation. Thus, the number of ordinary sessions rose from 36 to 63, extraordinary sessions from 6 to 14, adopted laws from 182 to 305, and adopted laws amending existing legislation from 69 to 161 . The number of questions put to the Prime Minister increased from 41 to 90 , the number of questions to members of the Government from 356 to 953, and the number of supplementary questions from 38 to 110. Similarly, at the level of committees (including the Commission for the Monitoring and Control of the Privatisation Process), the number of sittings increased from 303 to 827, and the number of agenda items rose from 1155 to 3040 . Finally, control and consultative hearings became regularly used at the committee level. Thus, control hearings increased from 2 to 15, and consultative hearings from 4 to 71 (see Table 8). 
Table 8. Activity of the working bodies of Parliament during the 24th convocation

\begin{tabular}{|c|c|c|c|c|c|}
\hline $\begin{array}{l}\text { Working body of } \\
\text { Parliament }\end{array}$ & $\begin{array}{c}\text { Number } \\
\text { of } \\
\text { meetings }\end{array}$ & $\begin{array}{c}\text { Duration of } \\
\text { meetings (days) }\end{array}$ & $\begin{array}{c}\text { Number of } \\
\text { items of the } \\
\text { agenda } \\
\text { discussed }\end{array}$ & $\begin{array}{l}\text { Number of } \\
\text { proposals of } \\
\text { the laws } \\
\text { discussed }\end{array}$ & $\begin{array}{l}\text { Number of } \\
\text { amendments } \\
\text { considered }\end{array}$ \\
\hline $\begin{array}{l}\text { Constitutional Issues } \\
\text { and Legislative } \\
\text { Committee }\end{array}$ & 144 & 144 & 968 & 646 & 3101 \\
\hline $\begin{array}{l}\text { Committee on Political } \\
\text { System, Judiciary and } \\
\text { Administration }\end{array}$ & 98 & 102 & 222 & 86 & 602 \\
\hline $\begin{array}{l}\text { Security and Defence } \\
\text { Committee }\end{array}$ & 52 & 59 & 121 & 21 & 77 \\
\hline $\begin{array}{l}\text { Committee on } \\
\text { International Relations } \\
\text { and European } \\
\text { Integration }\end{array}$ & 98 & 94 & 466 & 384 & 1 \\
\hline $\begin{array}{l}\text { Committee on } \\
\text { Economy, Finance and } \\
\text { Budget }\end{array}$ & 102 & 160 & 374 & 135 & 766 \\
\hline $\begin{array}{l}\text { Committee on Human } \\
\text { Rights and Freedoms }\end{array}$ & 78 & 81 & 215 & 35 & 217 \\
\hline $\begin{array}{l}\text { Gender Equality } \\
\text { Committee }\end{array}$ & 38 & 38 & 64 & 12 & 14 \\
\hline $\begin{array}{l}\text { Committee on } \\
\text { Tourism, Agriculture, } \\
\text { Ecology and Spatial } \\
\text { Planning }\end{array}$ & 38 & 47 & 94 & 39 & 250 \\
\hline $\begin{array}{l}\text { Committee on } \\
\text { Education, Science, } \\
\text { Culture and Sport }\end{array}$ & 32 & 30 & 56 & 29 & 166 \\
\hline $\begin{array}{l}\text { Committee on Health, } \\
\text { Labour and Social } \\
\text { Welfare }\end{array}$ & 72 & 77 & 202 & 57 & 285 \\
\hline $\begin{array}{l}\text { Administrative } \\
\text { Committee }\end{array}$ & 56 & 57 & 225 & 2 & - \\
\hline $\begin{array}{l}\text { Commission for } \\
\text { Monitoring and } \\
\text { Control of the } \\
\text { Privatisation Process }\end{array}$ & 19 & 23 & 33 & - & - \\
\hline Total & 827 & 912 & 3040 & 1446 & 5479 \\
\hline
\end{tabular}

Source: Parliament of Montenegro

Assessment

Growth in the number of committees during the 24th convocation, which was not reversed at the start of the current 25th convocation, seems to have done little to redress the strong imbalance in the workload of the committees. As Table 8 shows, the activity levels of committees differ markedly. The Legislative Committee and the Economy, Finance and Budget Committee stand out as having particularly high 
workloads. Staff numbers for committees, ranging between two and seven (in the case of the Committee for the Economy, Finance and Budget), broadly reflect these differing workloads.

In many European parliaments, the remit of the Economy, Finance and Budget Committee is shared by three or more committees, and there is a danger that some key tasks, such as the consideration of public accounts on the basis of reports by the State Audit Institution, are crowded out owing to the volume of other business. In fact, as committees are now also responsible for checking compliance with EU law, the already high workload of this committee has increased further. Against this background, it could be an attractive option to create two committees; one concentrating on the Economy and Finance, the other on Budgets and Accounts. The creation of sub-committees could also be considered.

The principles of allocating support staff to committees may also be adjusted in the future. So far, each committee has its own dedicated staff. There are certainly sound arguments for such a solution, notably the advantages of specialisation, as well as the establishment of close working relations between administrative staff and deputies. On the other hand, cross-cutting tasks, such as the checking of compliance of bills with EU law or the organisation of consultative and control hearings, may point in the direction of a matrix organisation.

\subsubsection{The Parliamentary Service}

The Parliamentary Service employs some 147 staff, including trainees. Its main tasks are stipulated in the Rules of Procedures of the Parliament, as are the responsibilities of its head, the Secretary General, who is assisted in leading the organisation by one Deputy and two Assistant Secretaries General. The organisational structure of the service is laid down in the Rulebook on Organisation and Systematisation. This Rulebook is adopted by the Secretary General after consultation of the Presidium (Collegium), and with the approval of the Administrative Committee of the Parliament.

The organisational development of the Parliamentary Service has been characterised by considerable dynamism for a number of years. The organisational structure has been modified, e.g. through the strengthening of the sector supporting the legislative and oversight functions of Parliament and the creation of a Research and Analysis Unit. Staff (including trainees) working for the Parliamentary Service increased from 87 at the end of 2009 to 147 by April 2013. Recruitment practices have changed with the introduction of special testing for parliamentary staff. Until the end of 2012, overall responsibility for recruitment still rested with the Human Resources Management Authority. The role of the Secretary General was formally restricted to choosing from a list of preselected shortlisted candidates. Since 1 January 2013, under the new Law on Civil Servants and Public Employees, recruitment has been fully devolved to Parliament.

Organisational development has been driven by strategic plans, notably the Action Plan for Strengthening of the Legislative and Oversight Role of the Parliament of Montenegro (December 2010-November 2011). This approach continued with the Action Plan for Strengthening of the Legislative and Oversight Role of the Parliament of Montenegro in 2013. The latter covers some 68 items across a range of fields of activity: some political, some administrative, including legislation and oversight and control, administrative and material capacities, and transparency and openness. The same approach is followed in 2014.

\section{Assessment}

The improvements in the Parliamentary Service are impressive. The Action Plan also shows clear awareness that improvements in political and administrative structures and processes are co-dependent. Thus far, it remains an open question as to what extent the deputies are fully aware of the changing Parliamentary Service culture. Inevitably, there is a time lag between organisational improvements and the provision of new services and their routine usage by parliamentarians. For example, since September 2010, it has been possible for deputies to commission research papers from the Section for Research, Analysis, Library and Documentation, however, until the end of 2013, about half of all papers were commissioned by the Secretary General or undertaken at the section's own initiative. Gradually, the MPs have started to request more research on their own initiative. 
The fact that deputies do not have access to dedicated office facilities at the seat of Parliament shapes their demands upon the Parliamentary Service and their relationship with the permanent administrative staff. With the exception of senior elected office holders, deputies come to Parliament to attend meetings and sittings, but it is not their regular place of work and they do not have assistants to act as permanent liaison with the Parliamentary Service. With the exception of the political leadership of Parliament and committee chairs, the co-operation between parliamentarians and administrators is intermittent rather than permanent.

\subsection{Key policy processes and instruments}

\subsubsection{Managing parliamentary business and inter-institutional relationships}

Managing the flow of parliamentary business, notably the legislative work programme and inter-institutional relationships (notably with the Government) falls primarily to the Collegium of the President and to committee chairs. To a considerable extent, the planning of Parliament is, by necessity, re-active, driven by the legislative programme of the Government and the requirements arising out of the $\mathrm{EU}$ accession process. These affect decisions on timetabling at the level of the plenary, and in the work plans adopted at the beginning of the year by committees.

\section{Assessment}

It was remarked upon above that, during the 24th convocation, a considerable number of government bills - 26 out of 147 adopted laws proposed by the Government in 2011, and 21 out of 73 adopted laws in 2012 - had not been contained in the annual Government Work Programme. Thus far, it appears that there are no restrictions on the number of bills to be considered in Parliament at any one time, and that Parliament has no influence over when bills are submitted.

There is also evidence to suggest that managing parliamentary business is becoming more politically contentious. Thus, in February 2013, at the request of the opposition, extraordinary sessions of Parliament were convened on three occasions, but, in each case, there was no majority for the adoption of an agenda, so that the sessions had to be closed. For some time, parts of the opposition also refused to attend committee meetings. This development indicates that there is a danger that the ability of the Presidium to arrange for effective parliamentary timetables may be more challenging.

\subsubsection{Legislative work}

The scrutiny and adoption of legislation is a central parliamentary contribution to policy making. There are detailed rules governing the parliamentary stages of the legislative process, both at the level of the Constitution and in the Rules of Procedure of the Parliament. The main stages, encompassing three readings, are set out in detail in the Rules of Procedure of the Parliament ${ }^{52}$. Parliament's legislative workload is high, as shown in Tables 9, 10 and 11.

Table 9. Total number of adopted acts during the 24th convocation

\begin{tabular}{|l|l|}
\hline Number of adopted acts & 466 \\
\hline Other acts & 235 \\
\hline Total number of adopted acts & 701 \\
\hline
\end{tabular}

Source: Parliament of Montenegro

52 The process is set out in the publication “How a Bill Becomes a Law”, available at Parliament's website. 
Table 10. Data on the sittings of Parliament for the 24th convocation

\begin{tabular}{|c|c|c|}
\hline Data & Ordinary Sessions & Extraordinary Sessions \\
\hline Numbers of sittings held & 63 & 14 \\
\hline Duration in days & 259 & 24 \\
\hline $\begin{array}{l}\text { Number of discussed items } \\
\text { of the agenda }\end{array}$ & 603 & 28 \\
\hline Number of adopted laws & $\begin{array}{c}300 \text { laws } \\
144 \text { laws on amendments to } \\
\text { laws } \\
5 \text { constitutional laws }\end{array}$ & $\begin{array}{c}5 \text { laws } \\
12 \text { laws on amendments to } \\
\text { laws }\end{array}$ \\
\hline $\begin{array}{l}\text { Number of other acts } \\
\text { adopted }\end{array}$ & 227 & 8 \\
\hline $\begin{array}{l}\text { Number of proposals of the } \\
\text { laws not adopted }\end{array}$ & 12 & 3 \\
\hline Number of interpellations & 2 & / \\
\hline $\begin{array}{l}\text { Number of motions of } \\
\text { no-confidence vote to the } \\
\text { Government }\end{array}$ & 2 & 1 \\
\hline
\end{tabular}

Source: Parliament of Montenegro

Table 11. Activity of parliamentary committees (including Privatisation Commission)

\begin{tabular}{|l|r|r|r|r|}
\hline Year & \multicolumn{1}{|c|}{$\begin{array}{c}\text { Number of } \\
\text { sittings }\end{array}$} & $\begin{array}{c}\text { Number of } \\
\text { considered items } \\
\text { on the agenda }\end{array}$ & $\begin{array}{c}\text { Number of } \\
\text { considered } \\
\text { proposals for laws }\end{array}$ & $\begin{array}{r}\text { Number of } \\
\text { considered } \\
\text { amendments }\end{array}$ \\
\hline $\mathbf{2 0 0 9}$ & 139 & 622 & 276 & 165 \\
\hline $\mathbf{2 0 1 0}$ & 221 & 848 & 420 & 1562 \\
\hline $\mathbf{2 0 1 1}$ & 313 & 1020 & 225 & 812 \\
\hline $\mathbf{2 0 1 2}$ & 154 & 550 & 355 & 2071 \\
\hline $\mathbf{2 0 1 3}$ & 369 & 1131 & 525 & 1940 \\
\hline
\end{tabular}

Source: Parliament of Montenegro

The task of legislative scrutiny falls primarily to committees during the first reading of a bill. It always involves the Legislative Committee, which scrutinises, among other things, compliance of bills with the Constitution and the legal system of Montenegro, and pays attention to legislative methodology and the responsible sectoral committee. All bills with budgetary implications are also considered by the Committee for Economy, Finance and Budget. Where necessary, other sectoral committees may also be involved.

\section{Assessment}

It is difficult to generalise about the thoroughness of legislative scrutiny at the committee stage and during the second and third plenary readings. In the standard case of government bills, the deputies' ability for scrutiny will be heavily influenced by the quality of the explanatory statements accompanying a bill, and by the briefings on bills prepared by the administrative staff servicing the committees. The number of amendments proposed is high, suggesting intensive scrutiny. Thus, in 2011/12, 1683 amendments were discussed, of which 1080 were adopted. Of those adopted, 644 had been proposed by 
committees. The Legislative Committee alone accounted for 584 adopted amendments. The next highest figure (20 amendments) was proposed by the Committee on the Political System, Judiciary and Administration. By contrast, the Committee on Economy, Finance and Budget proposed only 16 successful amendments. These figures must be treated with caution, but they suggest that scrutiny is principally focussed on legal issues, with an emphasis on ensuring compliance with the Constitution and the laws of Montenegro. Such an observation can be interpreted in at least two ways. First, the scrutiny of government bills for technical soundness and compliance with the Constitution and other legal norms by the Government, notably the Secretariat for Legislation, is to some extent deficient. In this case, Parliament would "correct" shortcomings in legislative technique and standards. Second, the Government and Parliament may be applying different standards.

The scope of the adjustments made in Parliament is not extensive in most cases, and is often a matter of different interpretation of legal and technical rules for law drafting, which should be overcome through more regular communication among the services of the Government and Parliament. In any case, technical amendments dominate, whilst successful substantive amendments by committees are not very frequent.

The instrument of consultative hearings under Article 73 of the Rules of Procedure of the Parliament, which allows committees to seek the opinion of experts, NGOs and state authority, is used sparingly by committees. As Table 12 shows, during the 24th convocation, the then Committee on International Relations and European Integration accounted for the bulk of consultative hearings.

Table 12. Consultative hearings during the 24th convocation

\begin{tabular}{|l|c|}
\hline \multicolumn{1}{|c|}{ Working body of Parliament } & Consultative hearings \\
\hline Constitutional Issues and Legislative Committee & - \\
\hline Committee on Political System, Judiciary and Administration & 1 \\
\hline Security and Defence Committee & 3 \\
\hline Committee on International Relations and European Integration & 50 \\
\hline Committee on Economy, Finance and Budget & 7 \\
\hline Committee on Human Rights and Freedoms & 2 \\
\hline Gender Equality Committee & - \\
\hline Committee on Tourism, Agriculture, Ecology and Spatial Planning & - \\
\hline Committee on Education, Science, Culture and Sports & - \\
\hline Committee on Health, Labour and Social Welfare & 5 \\
\hline Administrative Committee & 3 \\
\hline Commission for Monitoring and Control of the Privatisation Procedure & - \\
\hline Total & $\mathbf{7 1}$ \\
\hline
\end{tabular}

Source: Parliament of Montenegro

\subsubsection{Budgeting}

Parliament's powers and responsibilities in the field of budgeting are mainly detailed in the Law on Budget. The Rules of Procedure of the Parliament do not contain specific provisions relating to the annual budget procedure. At present, the annual bill on the Budget Law is submitted to Parliament in November, and the Budget Law must be adopted by 31 December. The bill is considered by the Committee for the Economy, Finance and Budget and the Legislative Committee; all other committees consider the bill within the scope of their competences, as obliged by the Conclusion of the Collegium, and submit opinions to the Committee for the Economy, Finance and Budget. 


\section{Assessment}

A key criticism of the current practice concerns the very short time available to Parliament for the scrutiny of the budget and accompanying acts. In practice, this leaves very little time to the Committee for Economy, Finance and Budget for the consideration of the draft and makes it even more difficult to co-ordinate concerns with other committees. The situation is aggravated by the fact that during the lengthy executive stages of the preparation of the budget bill, informal channels of communication between the relevant committees and the government ministries are weak. Nor is there a chance for Parliament to debate the main parameters of the budget prior to the finalisation of the bill by the Government and its submission to Parliament.

Despite great time pressures, the Economy, Finance and Budget Committee held a consultative hearing on the budget in December 2012. At this hearing, in addition to the substantive criticisms offered, the shortage of time for scrutiny, leading to a marginalisation of Parliament in the budgetary process, was highlighted as a key problem ${ }^{53}$.

Capacity concerns centred on the Economy, Finance and Budget Committee also affect the later stages of the budget process, including the monitoring of budget implementation and the consideration of public accounts. Leaving aside the scrutiny of the annual budget, the committee's time - and that of the seven administrative staff serving it - seems to a large extent to be taken up with legislative business for which the committee either acts as lead committee or is tasked with scrutinising budget impact. By contrast, the consideration of public accounts on the basis of information provided by the SAl seems of secondary concern. The creation of a public accounts sub-committee has been made moot, but no action has thus far been taken.

\subsubsection{Plenary and committee oversight and control}

Both the plenary and committees participate in executive oversight and control, while attempts have been made to widen the range of instruments at the disposal of Parliament and to intensify their use. At the level of the plenary, there are special sittings dedicated to the Prime Minister's hour and questions from deputies directed at members of the Government. Table 13 shows the use of these instruments for the 24th convocation.

Two points deserve highlighting. First, in common with other parliamentary democracies, the opposition parties account for the bulk of questions to the Government. Thus, whilst the Democratic Party of Socialists group submitted 62 questions (and one supplementary question), the Socialist People's Party group, as the largest opposition party, put 431 (and 39 supplementary questions) to the Government. Second, more intensive use was made of these instruments compared to the 23rd convocation. The number of special sittings rose from 6 to 14, questions to the Prime Minister from 41 to 90, questions to the Government from 356 to 953, and supplementary questions from 38 to 110. 2013). 
Table 13. Number of questions to the Prime Minister and members of the Government during the 24th Convocation

\begin{tabular}{|l|c|c|l|}
\hline Year & $\begin{array}{c}\text { Number of sittings dedicated } \\
\text { to the Prime Minister's Hour } \\
\text { and parliamentary questions }\end{array}$ & $\begin{array}{c}\text { Number of questions } \\
\text { posed to the Prime } \\
\text { Minister }\end{array}$ & $\begin{array}{c}\text { Number of parliamentary } \\
\text { questions }\end{array}$ \\
\hline 2009 & 3 & 16 & 197 and 17 supplementary \\
\hline 2010 & 3 & 18 & 190 and 38 supplementary \\
\hline 2011 & 5 & 35 & 358 and 35 supplementary \\
\hline 2012 & 3 & 21 & 208 and 20 supplementary \\
\hline Total & $\mathbf{1 4}$ & $\mathbf{9 0}$ & $\mathbf{9 5 3}$ and $\mathbf{1 1 0}$ supplementary \\
\hline
\end{tabular}

Source: Parliament of Montenegro

Next to these routine instruments, mention should also be made of parliamentary inquiries, interpellations and motions of confidence or no-confidence in the Government. Inquiries are regulated by the Law on Parliamentary Inquiry and the relevant provisions in the Rules of Procedure of the Parliament. A proposal to establish such an inquiry must be submitted by at least 27 MPs. Its main purpose is to investigate major issues that raise questions about the political accountability of the executive. During the 24th convocation, two such inquiries were proposed relating to the situation of the electro-energetic industry and allegations of corruption in the privatisation of Telecom Montenegro. One of these, dealing with the privatisation of Telecom Montenegro, was established and held a total of 13 meetings.

Interpellations serve to hear motions on the work of the Government, and two such interpellations were discussed during the 24th convocation. They dealt with the Government's policy towards local government, and economic policy and dealings with Credit Swiss Bank, respectively. Finally, during the same period, three motions of no-confidence in the Government were defeated.

At committee level, control hearings under Article 75 of the Rules of Procedure of the Parliament are the chief oversight instrument. Their purpose is to allow committees "to obtain information or professional opinions on specific issues" under their competence, and "specific issues related to establishing and implementing of the policy and law or other activities of the Government and state administration authorities, which cause obscurity, dilemmas or principle-related disputes". Control hearings allow for the questioning of members of the Government or its officials about issues relating to the execution of public policies. They may be summoned and must also provide written statements, if so required. As shown in Table 14, a total of 15 such hearings were conducted during the 24th convocation, in contrast to just two during the $23 \mathrm{rd}$. 
Table 14. Control hearings during the 24th convocation

\begin{tabular}{|l|c|}
\hline \multicolumn{1}{|c|}{ Working body of Parliament } & Control Hearings \\
\hline Constitutional Issues and Legislative Committee & - \\
\hline Committee on Political System, Judiciary and Administration & 1 \\
\hline Security and Defence Committee & 6 \\
\hline Committee on International Relations and European Integration & - \\
\hline Committee on Economy, Finance and Budget & 1 \\
\hline Committee on Human Rights and Freedoms & 4 \\
\hline Gender Equality Committee & - \\
\hline Committee on Tourism, Agriculture, Ecology and Spatial Planning & - \\
\hline Committee on Education, Science, Culture and Sports & 1 \\
\hline Committee on Health, Labour and Social Welfare & - \\
\hline Administrative Committee & - \\
\hline Commission for Monitoring and Control of the Privatisation Procedure & 2 \\
\hline Total & 15 \\
\hline
\end{tabular}

Source: Parliament of Montenegro

Discussion of the (usually) annual reports from public sector bodies, including independent regulatory bodies constitutes an important part of Committee oversight and control activity.

Two further points on Committee oversight should be noted. First, the Security and Defence Committee has a special role, in that it operates under the Law on Parliamentary Oversight in the Areas of Security and Defence and adopts an annual plan for oversight and control. Second, the Anti-Corruption Committee specialises in executive oversight and control, as its tasks are focussed on monitoring the fight against organised crime and corruption in the public sector. This committee is headed by a member of the opposition, as are some other committees with an oversight remit, including the Committee for Economy, Finance and Budget and the Commission for the Monitoring and Control of the Privatisation Process.

\section{Assessment}

Given that the task of executive oversight and control falls, in practice, primarily to the opposition under a parliamentary democracy, we may expect the use of the relevant parliamentary instruments be subject to political disputes. Since the start of the present 25th convocation, political conflict has centred on convening extraordinary sittings of Parliament and on control hearings (see Tables 10 and 14). As regards the latter, committees have had to agree on which control hearings to include in their annual work plans, which has proved controversial in several cases, with some proposals being rejected by the committee majorities ${ }^{54}$. There have also been instances where scheduled control hearings have been postponed because some deputies refused to attend ${ }^{55}$. Whilst members of the opposition allege that the Government is attempting to evade scrutiny, the governing parties are wary of turning control hearings into tribunal-style events.

In part, the political controversies surrounding control hearings and parliamentary enquiries and interpellations owe to their being so-called "fire alarm" instruments of oversight and control; that is, they are invoked if at least some deputies allege an executive failure of some sort. By contrast, "police patrols", i.e. instruments that would allow Parliament to carry out systematic assessments of executive action

54 As reported in the monthly editions of Open Parliament, Newsletter on the Parliament of Montenegro Performance. For example, this happened on 1 and 9 April 2013 in the Committee for the Political System, Judiciary and Administration. 
(notably the implementation of major laws and policies) do not yet exist. As a consequence, oversight and control are in danger of becoming highly partisan.

\subsubsection{European integration affairs}

The basic tasks of Parliament in the cross-cutting field of El are threefold: i) ensure appropriate parliamentary input to the negotiations; ii) monitor executive action in this field and ensure executive accountability; and iii) work towards the harmonisation of legislation with EU law. Prior to 2012 amendments to the Rules of Procedure of the Parliament, these responsibilities were largely concentrated in the Committee for International Relations and European Integration. Since then, there has been a Committee for International Relations and Emigrants and a Committee for European Integration. Under the amended Rules of Procedure of the Parliament, the latter is now responsible for overseeing EU accession negotiations and for issuing relevant opinions and guidelines, and also for assessing the "performance of the negotiating team". For this purpose, a consultative hearing on 11 March 2013 was organised to discuss the quarterly reports on the Stabilisation and Association Process and reports on the fulfilment of obligations arising from the Stabilisation and Association Agreement.

The task of ensuring legal harmonisation has now been decentralised to the sectoral committees.

Assessment

European integration policy is, of course, closely related to other aspects of foreign policy in the region and beyond. It is a positive sign that the Committee for International Relations and Emigrants and the Committee for European Integration have agreed to hold joint meetings - such as the consultative hearing of 29 March 2013 on the 2012 Performance Report of the Ministry of Foreign Affairs and European Integration (MFAEI).

Parliament must have able, effective structures and mechanisms to scrutinise the EU accession process led essentially by the Government. Electing a member of opposition as the chair of the relevant committee is a commendable practice. The decision to separate the oversight of negotiation (done in the Committee for European Integration) from the oversight of monitoring the approximation of legislation with the EU law and the implementation of the National Programme of Accession (NPA) (done by the line committees) requires well co-ordinated processes and sharing of expertise - potentially setting up an unnecessarily onerous, cumbersome or ineffectual practice. Deciding negotiation positions is essentially about deciding the kind and timeframe of commitments a country should take. The ability to implement these commitments and monitor this work effectively is part of the process. Separating those two functions might undermine the effectiveness of Parliament's scrutiny unless other mechanisms are adopted to counterbalance this potential. One such might be to have the chairs (or vice-chairs) of each line committee and political group also members of the Committee for European Integration, creating a link between discussions held within the line committees and within the European Committee.

The decision to regard negotiation positions as confidential is likely to hamper Parliament's scrutiny efforts. Moreover, it might also fuel general distrust towards the negotiation process. As the negotiation positions themselves essentially cover plans for reforms in relevant sectors, it is sensible that they be, to a large extent, open to public scrutiny and debate. Previous EU accession negotiations suggest that states that used an open and transparent system were better able to keep public trust towards the negotiation process than those that treated as highly confidential.

As discussed, there is no specific legal framework (parliamentary law) that would regulate the powers of Parliament in the field of El policy, in particular co-operation between the Government and Parliament. It is in the interest of the Government to limit parliamentary constraints when it comes to negotiating with the EU. However, given the extent to which political and legislative priorities in Montenegro are influenced by the accession process and its pervasive influence on both executive and parliamentary activity, executive-legislative tensions in this domain are likely to rise as adaptive pressures grow in sensitive policy areas. Also, the more Montenegro becomes integrated into the EU multi-level governance structures, the more oversight and control mechanisms within the domestic political and institutional context will be challenged. In short, both legislative powers and oversight and control are fundamentally transformed by progressive integration, which is why a growing number of Member States have decided 
to develop detailed legal frameworks at the level of constitutional or parliamentary law in order to safeguard Parliament's role. 


\section{THE SIGMA PROGRAMME}

SIGMA (Support for Improvement in Governance and Management) is a joint initiative of the OECD and the EU, principally financed by the EU. SIGMA has been working with countries on strengthening public governance systems and public administration capacities for over 20 years.

SIGMA currently works with:

- Albania, Bosnia and Herzegovina, the former Yugoslav Republic of Macedonia, Kosovo*, Montenegro, Serbia, and Turkey as EU candidate and potential candidate countries

- Algeria, Armenia, Azerbaijan, Egypt, Georgia, Jordan, Lebanon, Moldova, Morocco, Tunisia and Ukraine as EU Neighbourhood countries

- $\quad$ Croatia as a new EU Member State

SIGMA provides assistance in 5 key areas:

i) Civil service and public administration organisation and functioning

ii) Policy making

iii) Public finance and audit

iv) Public procurement

v) Strategy and reform

SIGMA assesses:

- Governance systems and institutions

- $\quad$ Legal frameworks

- $\quad$ Reform strategies and action plans

- Progress in reform implementation

and provides:

- Methodologies and tools to support reforms

- Recommendations on improving laws and administrative arrangements

- $\quad$ Advice on the design and implementation of reforms

- Opportunities to share good practice from a wide range of countries

- $\quad$ Policy papers and multi-country studies.

For further information on SIGMA, consult our website: www.sigmaweb.org

\section{(C) OECD 2014}

All requests for permission to reproduce or translate this publication for commercial or non-commercial purposes should be submitted to rights@oecd.org.

* This designation is without prejudice to positions on status, and is line with UNSCR 1244/1999 and with the ICJ opinion on the Kosovo declaration of independence. 